\title{
Support for populist candidates in the 2016 presidential elections predicted by declining social capital and an increase in suicides.
}

\author{
Lynch, $\mathbf{R}^{\mathrm{a}, 2}$, Lynch, $\mathbf{N}^{\mathrm{b}}$, Chapman, $\mathbf{S}^{\mathrm{a}}$, Briga, $\mathbf{M}^{\mathrm{a}}$, Lynch, $\mathrm{E}^{\mathrm{a}}$, and Helle, $\mathbf{S}^{\mathrm{a}}$ \\ ${ }^{\mathrm{a}}$ University of Turku, Turku, Finland; ${ }^{\mathrm{b}}$ Mamaroneck High School, Mamaroneck, NY \\ This manuscript was compiled on September 6, 2019
}

\begin{abstract}
The rising support for populist candidates has received considerable attention recently, and the conditions which give rise to populism are of broad scientific interest. Populism is seen as a revolt by 'common people' against 'corrupt elites'. The most common explanations for its recent surge are the Economic Insecurity Hypothesis - populism is a consequence of changes in the workforce stemming from globalization - and the Cultural Backlash Hypothesis - populism is a reaction to changes in societal values and norms. Tests of these ideas have shown mixed results and frequently fail to take into account fundamental transformations in social structures that accompany major economic and cultural change. Here we propose and test what we call 'the social isolation hypothesis', which hypothesizes that the rise in support for populism is the result of declining of social capital, networks and relationships which together conspire to increase loneliness and undermine mental health. Using longitudinal census data from the American Community Survey, mortality data from the Center for Disease Control, and results from the 2016 United States presidential elections and primaries, we find that support for populist candidates Bernie Sanders and Donald Trump is strongly predicted by changes in variables related to social isolation - per capita deaths from suicide or alcohol, and an overall decline in social capital - in the eight years preceding the 2016 election. These results support the idea that the deterioration of the strength of social bonds can undermine confidence in existing organizations and institutions and affect voting behavior.
\end{abstract}

Populism | social capital | political polarization | deaths of despair|suicide|alcoholism

"All of us, from cradle to grave, are happiest when life is organized as a series of excursions, long or short, from the secure base provided by our attachment figures."(1)

$\mathbf{T}$ he results of the 2016 presidential election in the United States present a unique opportunity to explore the conditions that give rise to populist movements which are seen to pit the virtuous common people against an established class of corrupt elites(2). At the beginning of the 2016 presidential primary season, Hillary Clinton (Democrat) and Jeb Bush (Republican), traditional representatives of their respective parties, were seen by many as the inevitable nominees(3). By the end of that year, however, the insurgent campaigns of Donald Trump (Republican) and Bernie Sanders (Democrat), both of which were widely seen as populist uprisings, had thrown both major parties into turmoil(4). Sanders, an independent senator from Vermont, narrowly lost the nomination for the Democratic party, and Donald Trump, considered a long shot by most political insiders, won the Republican nomination.

The fallout from this historic election is still being felt and a consensus on which factors produced this extraordinary outcome has yet to emerge. Some of the most common explanations for Trump's victory and Sanders surprising competitiveness focus on economics and cultural issues. For example, many have explored the political abandonment of working class voters in favor of professional elites by both parties(5); why poor, rural, and less educated whites vote against their economic interests(6), cultural explanations (7), the role of religion (8), the influence of lobbyists and corporations (9), the impact of social media(10), and the increasing importance of identity politics(11). Overall, however, the candidacies of both Trump and Sanders have been widely viewed as populist revolts(12). In general, populists separate the world into two categories - the 'corrupt elites' and the 'righteous common people' and its emergence signals a sharp break from the political establishment(13). Populist leaders are frequently viewed by supporters as fighting against entrenched power, elites, and traditional ideas (14). Although who is characterized as an "elite" depends on one's political beliefs(15), populist movements arising on both the left and the right usually benefit from an overall decrease of trust in politicians. (16).

Explanations for the increasing support for populist can- 
didates can be grouped into two broad and overlapping categories: economic distress - Economic insecurity hypothesis - and rapid cultural change - Cultural backlash hypothesis. Most economic explanations rely on a theory of economic inequality(7), which suggests that increasing economic inequality or stagnant wages resulting from e.g. globalization have fueled popular resentment of the political classes(17). In support of this view, major financial shocks, such as the subprime mortgage crisis in 2008, are frequently followed by an increase in support for populist candidates(18), with a greater severity of crisis positively correlated with greater populist surges(19). Financial crises may also radicalize voters, such that the share of centrists decreases and the proportion of 'extremists' (i.e. on the fringes of the left-right political spectrum) increases(20) and the 2008 economic collapse is frequently cited as a cause for the recent rise in populism(19). Alternatively, the 'Cultural Backlash hypothesis'(2) sees populism as a response to progressive cultural change and the increasing influence of a multiculturalist worldview (e.g. environmentalism, gender equality, human rights) adopted by elites(21). This theory is frequently tied to arguments about how racism, sexism, and xenophobia drive support for populist candidates(22), though it is more frequently asserted by media pundits(23) than empirically studied. Arguments implicating cultural change may also be tied to political polarization, implicating the increased focus on non-overlapping identities such as race, gender, or religious orientation for promoting populism and an 'us vs them' mentality(24). Cultural explanations, however, may also intersect with economic factors and frequently rely on resentment fueled by the perception that some groups have gained more from globalization than others $(25)$.

As an alternative to economic or cultural change theories, we propose the 'social isolation hypothesis' which posits that the breakdown of social networks may lead to social isolation and, consequently, anger towards traditional politicians and political parties. Social interactions play a central role in the lives of mammals (see review by Silk et al.(26)), and in humans, strong social bonds are critical for the maintenance of physical and mental health (27). These relationships have important effects on the health of individuals, and their breakdown can result in isolation(28), loneliness(27), addiction(29), and even death(30). The widespread degeneration of social networks are not only harmful to individuals, but can also damage the communities in which they live(31). The corrosive effects of deteriorating social networks have also been implicated in mass political movements(32).

The United States has experienced a precipitous decline in social capital - the norms of trust and reciprocity that enable people to act collectively - and this drop has been particularly acute in many of the less educated and less populated regions of the country(28). People in these communities interact with each other less frequently, have fewer close social relationships, are more distrustful, volunteer less, and take less active roles in their neighborhoods(33). Trust in one's neighbors and countrymen(28), as well as the number of close relationships(34) have fallen dramatically over the last few decades and trust in both media and government have reached an all time low(35). Life ex- pectancy is a particularly useful way to measure the health of a communities and social networks. Émile Durkheim argued that suicides, in particular, are caused by a decline in the strength of social networks and bonds(31), and it is well known that attachment disorders play an important role in both addiction(29) and suicide(36). Within the United States, variance in life expectancy, especially amongst the less educated,rose sharply between 2010 and 2016(37). It has been suggested that social isolation is responsible for America's staggering increase in substance abuse and suicide rates(30), which have now become the leading causes of death for Americans under the age of 45(38). Case and Deaton(39) have called these "deaths of despair", contending that these patterns move together across birth cohorts in concert with other social dysfunctions, such as the decline of marriage, social isolation, and detachment from the labor force(30). Overall, it is clear that theories of both social capital(33) and attachment(1) predict that social relationships are crucial for mental health and that their absence can result in dire consequences for individuals and communities. A potential consequence of fewer social bonds, rising rates of addiction and alcoholism, and the general loss of trust in one's neighbors is that individuals will be more tolerant of risk when faced with these losses(40)(see Supplementary Materials: Prospect theory). This leads to the prediction that voters may be more willing to accept the higher risk of supporting an unknown outsider (e.g. Trump or Sanders) when faced with the collapse of social networks and relationships. A key unresolved question, however, is whether these major social changes lead to or are merely coincident with the rise of populism.

Much of the discussion about the recent rise in support for populist candidates has involved viewing it as a response to rapid economic, and cultural change, but deeper insight into these causes first requires a better understanding of how individuals respond to changes in their social networks. Here, we test the applicability of these theories to the rise of populist candidates in the 2016 presidential race* and examine how changes in social capital, economic conditions, and key demographic variables that influence cultural change and norms, such as those resulting from immigration, were associated with support for Donald Trump and Bernie Sanders. In particular, we use county-level mortality data on suicides, drug overdoses, and deaths due to alcohol, as well as a social capital index as proxies for the health and strength of social bonds to predict support for presidential candidates in the 2016 primaries and general election. Overall, we aim to analyze how changes in pivotal social, demographic, and economic factors in the aftermath of the 2008 global financial crisis were associated with support for populist candidates and their opponents. We hypothesize that individuals living in counties that experienced greater declines in social networks were more susceptible to populist appeals and make the following pre-registered(42) predictions: Voters in counties that experienced a greater increase in per capita suicides (P1), deaths due to alcohol (P2), drug overdoses (P3), and an overall decrease in a social capital index(P4) will be more likely to support populist

\footnotetext{
Although none of the presidential candidates from either major political party were considered to be populist in 2008 or 2012, the popularity of Republican presidential candidate John McCain's running mate Sarah Palin is widely seen as an important early sign that populist candidates were beginning to gain support in the aftermath of the 2008 financial crisis(41).
} 
TRUMP VS vs. CLINTON[R $\left.{ }^{2}=0.40\right]$

SANDERS vs. CLINTON $\left[\mathrm{R}^{2}=0.66\right]$

TRUMP vs. KASICH $\left[R^{2}=0.76\right]$

\begin{tabular}{|c|c|c|c|c|c|c|c|c|c|c|c|c|c|c|c|}
\hline \multirow{3}{*}{ PREDICTOR } & \multirow{2}{*}{\multicolumn{2}{|c|}{$\begin{array}{l}\text { PREDICTED TRUMP } \\
\text { Iqr range }\end{array}$}} & \multirow{3}{*}{$\begin{array}{c}\text { EFFECT SIZE } \\
X \\
\text { Pred(+/-) } \\
\end{array}$} & \multicolumn{2}{|c|}{ HYPOTHESIS } & \multirow{2}{*}{\multicolumn{2}{|c|}{$\begin{array}{l}\text { PREDICTED SANDERS } \\
\text { Iqr range }\end{array}$}} & \multirow{3}{*}{$\begin{array}{c}\text { EFFECT SIZE } \\
x \\
\text { Pred(+/-) } \\
\end{array}$} & \multicolumn{2}{|c|}{ HYPOTHESIS } & \multirow{2}{*}{\multicolumn{2}{|c|}{$\begin{array}{l}\text { PREDICTED TRUMP } \\
\text { Iqr range }\end{array}$}} & \multirow{3}{*}{$\begin{array}{c}\text { EFFECT SIZE } \\
x \\
\text { Pred }(+/-)\end{array}$} & \multicolumn{2}{|c|}{ HYPOTHESIS } \\
\hline & & & & Pred & Support & & & & \multirow{2}{*}{$\begin{array}{l}\text { Pred } \\
+/-\end{array}$} & \multirow{2}{*}{$\begin{array}{l}\text { Support } \\
\boldsymbol{V} / \mathbf{x}\end{array}$} & & & & \multirow{2}{*}{$\begin{array}{l}\text { Pred } \\
+/-\end{array}$} & \multirow{2}{*}{$\begin{array}{l}\text { Support } \\
\boldsymbol{V} / \mathbf{x}\end{array}$} \\
\hline & 25 th & 75 th & & & & 25 th & 75 th & & & & 25 th & \multirow{2}{*}{75 th } & & & \\
\hline \multicolumn{15}{|l|}{ Social change [2008-2016] } & \\
\hline Increase in suicides & $53.2 \%$ & $57.2 \%$ & 4.7 & + & $\checkmark$ & $46.1 \%$ & $47.9 \%$ & 2.2 & + & $v$ & $80.5 \%$ & $81.0 \%$ & 0.9 & + & $v$ \\
\hline Increase in deaths dues to alcohol & $54.1 \%$ & $55.7 \%$ & 1.8 & + & $\checkmark$ & $46.3 \%$ & $47.4 \%$ & 1.3 & + & $\checkmark$ & $80.4 \%$ & $81.1 \%$ & 0.8 & + & $v$ \\
\hline Increase in drug overdoses & $57.6 \%$ & $56.0 \%$ & -1.0 & + & x & $47.1 \%$ & $46.7 \%$ & -0.2 & + & $\times$ & $80.5 \%$ & $81.0 \%$ & 0.4 & + & 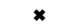 \\
\hline Increase in social capital & $57.0 \%$ & $53.1 \%$ & 3.6 & - & $v$ & $47.8 \%$ & $46.1 \%$ & 1.6 & - & $v$ & $81.2 \%$ & $80.3 \%$ & 1.4 & - & $v$ \\
\hline Mean Effect of Social factors & & & $2.3^{*}$ & & $v$ & & & $1.2^{*}$ & - & $v$ & & & $0.9^{*}$ & & $v$ \\
\hline \multicolumn{16}{|l|}{ Demographic change [2008-2016] } \\
\hline Increase in percent foreign born & $55.1 \%$ & $54.7 \%$ & -0.7 & + & $\boldsymbol{x}$ & $47.7 \%$ & $46.7 \%$ & -1.8 & + & $\mathbf{x}$ & $81.1 \%$ & $80.7 \%$ & -1.2 & + & x \\
\hline Increase in percent white & $47.0 \%$ & $54.2 \%$ & -13.3 & - & x & $44.8 \%$ & $46.6 \%$ & -3.3 & - & $\times$ & $78.6 \%$ & $80.5 \%$ & -5.7 & - & * \\
\hline Increase in population & $59.7 \%$ & $55.8 \%$ & 3.5 & - & $v$ & $44.8 \%$ & $46.3 \%$ & -1.3 & - & $\boldsymbol{x}$ & $85.0 \%$ & $81.7 \%$ & 5.1 & - & $v$ \\
\hline Mean Effect of Demographic factors & & & -3.5 & & * & & & -2.1 & & * & & & -0.6 & & $\boldsymbol{x}$ \\
\hline \multicolumn{16}{|l|}{ Economic change [2008-2016] } \\
\hline Increase in male unemployment & $56.3 \%$ & $53.5 \%$ & -1.3 & + & x & $47.4 \%$ & $46.3 \%$ & -0.5 & + & × & $81.1 \%$ & $80.4 \%$ & -0.6 & + & x \\
\hline Increase in female unemployment & $54.6 \%$ & $54.9 \%$ & 1.6 & + & $v$ & $46.8 \%$ & $46.8 \%$ & 0.1 & + & $v$ & $80.7 \%$ & $80.7 \%$ & 0.6 & + & $v$ \\
\hline Increase in median household income & $54.7 \%$ & $54.9 \%$ & -0.1 & - & x & $46.3 \%$ & $47.7 \%$ & -0.8 & - & $\mathbf{x}$ & $80.8 \%$ & $80.6 \%$ & 0.1 & - & $v$ \\
\hline Increase in percent with bachelors degree & $62.6 \%$ & $53.6 \%$ & 5.0 & - & $v$ & $48.1 \%$ & $46.6 \%$ & 0.8 & - & $v$ & $83.3 \%$ & $80.3 \%$ & 2.8 & + & $v$ \\
\hline Mean Effect of Economic factors & & & 1.3 & & $v$ & & & -0.1 & & x & & & 0.7 & & $v$ \\
\hline
\end{tabular}

Table 1. Predicted vote percentage across the interquartile range (25th to 75 th percentile of the data range), standardized effect sizes(43) and whether the parameter estimate supports the prediction for factors affecting the number of votes that Trump [1] received in comparison to Clinton [0] in 2016,that Sanders [1] received in comparison to Clinton [0] in the 2016 Democratic primary and that Trump [1] received in comparison to Kasich [0] in the 2016 Republican primary (left to right). Parameter estimate means and $97.5 \%$ credibility intervals are show in Supplementary materials: Tables S1-S3. All changes (i.e. increases) were calculated as the difference between 2016 and 2008 except social capital which was calculated as the difference between 2014 and $2005^{\star}$. Suicides, drug overdoses and deaths due to alcohol are entered as rates per $\mathbf{1 0 0 , 0 0 0}$ individuals and were obtained from the Center for Disease control. Social capital is centered at zero and a one point difference in either direction represents one standard deviation. Population and median household income were both logged. Percent with a bachelors degree, percent foreign born, household income, unemployment rates, percent white and population are based on estimates from the Census Bureau American Community Surveys (ACS) from 2008 and 2016.

candidates in the 2016 presidential election and primaries. In order to compare the relative effects of a decline in social capital with other economic and demographic factors that are well known to have had an important influence on these elections we also simultaneously examine how changes in key demographic factors (e.g. population density, racial makeup, and percentage of immigrants) and economic factors (e.g. education level, income, and unemployment rate) affect support for populist candidates.

\section{Results}

We ran three generalized linear mixed models with Bayesian estimation analyzing the proportion of votes given in three elections in 2016 for: (i) Trump vs Clinton in the general election, and (ii) Sanders vs Clinton in the Democratic primary and (iii) Trump vs Kasich in the Republican primary. Our novel finding is that the measures of social decline standardized by their maximum possible range(43) were more strongly associated with support for Trump in both the general election and Republican primary and with Sanders on the Democratic primary (see Table 1) compared to measures of economic decline and demographic change. With the exception of changes in total population, all of the same factors that predicted support for Sanders in the Democratic primary also predicted support for Trump in the general election. We present these results within three broad categories of social, demographic, and economic change that occurred between the 2008 financial crisis and the 2016 elections (see Table 1, Figures 2-4 and Supplementary Materials Tables S1-S3 and Figures S2a-c). For interactive map showing all variables entered into these models by county click map

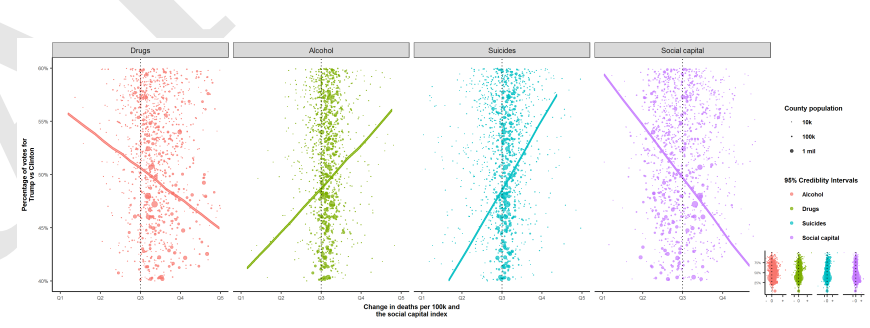

Figure 1: The percentage of votes received by Trump in comparison to Clinton in the 2016 General presidential election (y-axis) plotted against the number of deaths due to drug overdose (orange), alcohol poisoning (green), suicide (blue) and a social capital index (purple). Points are model predictions for each US counties (scaled by their population in 2016) and shaded lines are predicted posterior distribution 95\% credibility intervals (see Supplementary Materials: Table S1). Xaxis tick mark labels demarcate boundaries between quintiles (e.g. Q1 is 0 to $20 \%$ of shown $\mathrm{x}$ axis range) for each category on the $\mathrm{X}$-axis. Main plot shows the central mass of counties and posterior distribution, and the inset (bottom right) shows the entire range (all counties and entire posterior distribution). For interactive figure with county names, state, populations and mortality for each county click Fig1 


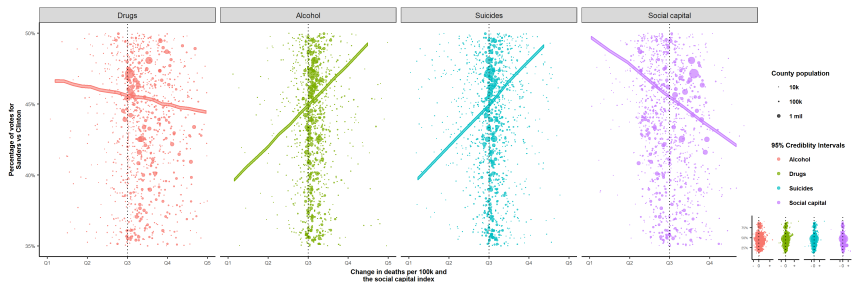

Figure 2: The percentage of votes received by Sanders in comparison to Clinton in the 2016 Democratic primary (y-axis) plotted against the number of deaths due to drug overdose (orange), alcohol poisoning (green), suicide (blue) and a social capital index (purple). Points are model predictions for each US counties (scaled by their population in 2016) and shaded lines are predicted posterior distribution $95 \%$ credibility intervals (see Supplementary Materials: Table S2). X-axis tick mark labels demarcate boundaries between quintiles (e.g. Q1 is 0 to $20 \%$ of shown $x$ axis range) for each category on the X-axis. Main plot shows the central mass of counties and posterior distribution, and the inset (bottom right) shows the entire range (all counties and entire posterior distribution). For interactive figure with county names, state, populations and mortality for each county click Fig2

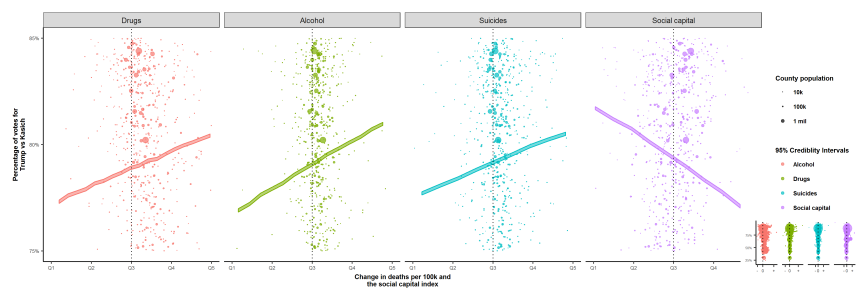

Figure 3: The percentage of votes received by Trump in comparison to Kasich in the 2016 presidential primary ( $y$-axis) plotted against the number of deaths due to drug overdose (orange), alcohol poisoning (green), suicide (blue) and a social capital index (purple). Points are model predictions for each US counties (scaled by their population in 2016) and shaded lines are predicted posterior distribution 95\% credibility intervals (see Supplementary Materials: Table S3). X-axis tick mark labels demarcate boundaries between quintiles (e.g. Q1 is 0 to $20 \%$ of shown $x$ axis range) for each category on the $\mathrm{X}$-axis. Main plot shows the central mass of counties and posterior distribution, and the inset (bottom right) shows the entire range (all counties and entire posterior distribution). For interactive figure with county names, state, populations and mortality for each county click Fig3

An increase in both per capita suicides and alcoholrelated deaths were positively associated with an increased likelihood of voting for populist candidates in each of the three elections (see Table $1^{\dagger}$ and Figures 1-3). Together, these results provide broad support for predictions (P1-P2). In the general presidential election, the model predicts that voters living in an average county (i.e. using the United States mean values for all other variables entered into the model) in which there was a net decrease of 2.3 suicides per 100k between 2008 and 2016 (25th percentile) were $4.1 \%$ [5.2 million votes] less likely to vote for Trump in the general election than those in counties that experienced a net increase of 9.8 suicides per $100 \mathrm{k}$ ( $75 \mathrm{th}$ percentile). The same increase across the interquartile range IQR (middle $50 \%$ of the data) in deaths due to alcohol (i.e. from a 0.21 decrease to a 7.2 increase) is expected to result in a $1.6 \%$ greater likelihood of voting for Trump against Clinton. In the Democratic primary, the model predicts that an increase in per capita suicides across the IQR increases the likelihood that voters would support Sanders by $1.8 \%[561,266$ votes], and that the same relative change in deaths due to

${ }^{\dagger}$ Results were similar if parameter estimates were standardized by multiplying them by the standard deviation of their observed range (Cohens d)(44)(see Supplementary materials Table S5) alcohol would result in a $1.1 \%$ increase. In the Republican primary the model predicts that an increase in suicides from the 25 th to 75 th percentile would increase the likelihood of voting for Trump against Kasich by $0.5 \%$ [83,382 votes], and that the same relative change in deaths due to alcohol would result in a $0.7 \%$ increase in support for Trump (see Table 1 for predictions across the IQR and $97.5 \%$ parameter estimate credibility intervals for all variable entered into these models). Although per capita deaths from drug overdoses predicted voting for Trump in the GOP primary, it did not predict support for Trump in the general election or for Sanders in the DNC primary, and therefore fails to provide support for (P3)(Table 1 and Figures 2-4). Voters in counties that experienced a per capita decrease of 0.02 drug overdoses (25th percentile) vs. an increase of 11.66 ( 75 th percentile) were predicted to be $1.6 \%$ more likely to vote for Trump in the general election, $0.4 \%$ more likely to vote for Sanders, but $0.5 \%$ less likely to vote for Trump as compared to Kasich in the GOP primary. A decline in social capital positively predicted support for Trump in both the general election and the primary and for Sanders in the primary (Table 1 and Figures 2-4). These results provide support for (P4). Voters in counties that experienced an overall increase in social capital (i.e. the 25 th percentile $[+0.42])$ vs those that experienced an overall decrease $(75$ th percentile [-0.42]) were predicted to be $3.9 \%$ less likely to vote for Trump in the general election, $1.7 \%$ less likely to vote for Sanders and $0.9 \%$ less likely to vote for Trump against Kasich in the GOP primary.

Key demographic changes between 2008 and 2016 were inconsistent predictors of voting for populist candidates. Overall, voters in counties that better retained their nativeborn and white populations (i.e. received fewer immigrants and other non-white racial groups) were more likely to vote for Trump in the general election and the GOP primary, and for Sanders in the DNC primary, while declining population size predicted support for Trump in the GOP primary and the general election (see Table 1 and Supplementary Materials: Tables S1-S3 and Figures S2a-c). For example, voters in an average county that experienced a $0.2 \%$ decrease (25th percentile) vs a $0.7 \%$ increase ( 75 th percentile) in the percentage of residents who were foreign born were predicted to be $0.4 \%$ more likely to vote for Trump in the general election $1.0 \%$ more likely to vote for Sanders in the DNC, and $0.4 \%$ more likely to support Trump in the GOP primary. The same pattern is seen for counties that retained their overall whiteness. Voters in counties that experienced a $2.0 \%$ decrease (25th percentile) vs. those in counties that only experienced a $0.1 \%$ decrease ( 75 th percentile) in the proportion of residents who are white were predicted to be $7.2 \%$ less likely to vote for Trump in the general election, $1.8 \%$ less likely to vote for Sanders in the DNC primary, and were $1.9 \%$ less likely to support Trump in the GOP primary. Declining population, meanwhile, predicts support for both Trump in the general election and the GOP primary, but does not predict support for Sanders. Voters in counties that experienced a $2 \%$ decrease in population (25th percentile) vs. those in counties that experienced a $2 \%$ increase (75th percentile) were predicted to be $3.9 \%$ more likely to vote for Trump in the general election, $3.2 \%$ more likely to support for Trump in the GOP primary, but $1.5 \%$ less likely 
to vote for Sanders.

The percent of the population that graduated from a four year college was the only factor suggesting economic decline that consistently (and negatively) predicted support for populist candidates across all three elections. In contrast, increasing median income predicted support for Trump in the general election and Sanders in the primary while increasing male and female unemployment had either no practical effect or predicted reduced support for populist candidates (Table 1 and Supplementary Materials: Tables S1-S3 and Figures S2a-c). For example, voters in counties that experienced a $0.5 \%$ decrease (25th percentile) vs a $0.14 \%$ increase (75th percentile) in male unemployment were predicted to be $2.8 \%$ more likely for Trump in the general election, $1.1 \%$ more likely to vote for Sanders, and $0.7 \%$ more likely to vote for Trump in the GOP primary. The change in female unemployment rates across counties were far less variant than male unemployment rates ( 3 -times less), and therefore had a much smaller practical impact on our models. A $0.02 \%$ decrease (25th percentile) vs. a $0.02 \%$ increase $(75$ th percentile) in female unemployment rates resulted in $0.2 \%$ fewer predicted votes for Trump in the general election, and had almost no influence on votes for Sanders or Trump in the Democratic and GOP primaries, respectively. Decreasing median household income decreased the likelihood that individuals voted for Sanders, while having almost no impact on Trump in the general election or in the primary against Kasich in the GOP primary.

Voters in counties that only experienced a $3 \%$ increase ( 25 th percentile) vs. a $12 \%$ increase ( 75 th percentile) in median household income were predicted to be $0.2 \%$ less likely to support Trump in the general election, $1.4 \%$ less likely to support Sanders in the primary, and $0.2 \%$ more likely to support Trump in the primary. Meanwhile, an increasing percentage of the population with a bachelor's degree negatively and strongly predicted populist support in all three elections. Voters in counties that only experienced a $0.6 \%$ increase (25th percentile) vs a $2.4 \%$ increase ( 75 th percentile) were $9 \%$ more likely to vote for Trump in the general election $(62.6 \%$ vs. $53.6 \%), 1.5 \%$ more likely to vote for Sanders ( $48.1 \%$ vs. $46.6 \%$ ), and $3 \%$ more likely to vote for Trump in the primary ( $83.3 \%$ vs. $80.3 \%)$.

\section{Discussion}

Our study provides novel evidence suggesting that in the years following the financial crisis in 2008 and leading up to the 2016 elections, support for populist candidates was associated with factors that have been linked with deteriorating social networks - declining social capital, rising suicides, and deaths due to alcohol - rather than those linked to demographic and economic decay (e.g. an increase in male unemployment or decrease in household income). Because social relationships have important effects on the health of individuals and their communities, the breakdown of these networks can have consequences on a broad scale. This study suggests that the depletion of social capital and increasing social isolation may play pivotal roles in generating outrage against 'elites', globalization, or other institutions that establish norms and represent power which can ultimately generate support for populist candidates who are best able to channel this anger.
Across all three elections we analyzed, factors that have been previously linked to declining social networks - increasing suicides P1, increasing deaths from alcohol P2, and reduced social capital $\mathbf{P} \mathbf{4}$ - all predicted support for populist candidates. Alcoholism (45) and suicide (46), for example, are commonly viewed as attachment disorders and frequently follow changes in social networks, such as those that accompany globalization and cultural displacement(47). Suicides in particular are seen to signal increasing loneliness, social detachment and diminished mental health and are symptomatic of a breakdown in social networks(48). The positive link between suicide rate and populist sentiment reported here may be of particular concern and suggests that the rise in populism reflects a public health crisis. Although rising drug overdoses positively predicted support for Trump in the GOP primary, it did not predict support for him in the general election or for Sanders in the DNC primary P3.This may be explained by differences in the availability of drugs across the country. Unlike alcohol, Rossen et al. 2014(49) found that access to opiates (a main cause-of-death in drug overdoses) exhibits far more spatial dependence (i.e. counties with high drug poisonings are located closer together than we would expect at random). Therefore, drug overdoses may be more dependent upon factors that are unrelated to social decay, such as drug availability(50), rates of employment related disability(51), access to prescriptions for pain relievers(52), and drug trafficking routes(49). Therefore, drug overdose rates may not be as useful a measure of social network decline as deaths due to alcohol poisoning or suicides.

Demographic change and factors related to immigration were frequently negative predictors of support for Trump and Sanders. The hypothesis that populist-voting communities are under demographic threat from immigration or changes in minority representation in the local population(53) received no support. Surprisingly, we found the opposite pattern: counties that better retained their native born and white populations were more likely to vote for populist candidates. The exception to this pattern was population decline, which did predict support for Trump in the primary and in the general election. However, population decline may just as easily be categorized under factors related to social change - e.g. if individuals move away from dying communities, the social support networks of those who remain may be weakened. Therefore, if the 'cultural backlash hypothesis' (2) is valid, it is unlikely to arise from locally-experienced 'threats', and is more likely to emerge from 'threat' perceived on the national level, such as from television or the internet.

We also found little support for the 'economic insecurity hypothesis' and economic change was a poor predictor for the rise of populism in all three models. We did find evidence of a sex-biased effect of unemployment, however, whereby increased male unemployment consistently predicted support for the more traditional non-populist candidate, while rising female unemployment had the opposite result. The absolute effect of increasing female unemployment rates on voting behavior were small (see Results and Supplementary materials: Figures S2a-c), though. This is primarily attributed to men having experienced far higher (6X) rates of unemployment following the 2008 financial cri- 
sis than women(54). Median household income also failed to support hypotheses implicating economic distress as a factor behind the rise of populism. Notably, a key exception to the overall failure of indices of economic decline to predict support for populist candidates was the impact of education. An increasing percentage of the population that received a bachelor's degree was a strong and consistent predictor of support for traditional non-populist candidates, which suggests that, although these populist communities are no worse off in terms of unemployment or income, they may be losing social status. This is consistent with arguments that highly educated social elites are more often the targets of populist resentment than economic elites(55), and that bastions of populist support are falling behind in higher education(25). In general, however, hypotheses suggesting that economic factors are responsible for generating populist sentiment did not receive consistent support in any of our models.

The results of this study can be understood through the lens of cognitive psychology. Prospect Theory, proposed by behavioral economists Daniel Kahneman and Amos Tversky (1979), predicts that voters do not make decisions solely on the desired outcome, but, rather, are expected to rely on heuristics that depend on how they value losses vs. gains(56). For instance, voters are expected to be more averse to risk when they are faced with potential or actual losses and are there are more willing to take risks to avoid locking in losses. Therefore, populist candidates offering anti-elitist and what are frequently riskier policies may be more appealing to individuals who are more anxious about the future, feel isolated or perceive threats to their welfare. In support of the idea that loss aversion and threats to one's emotional, psychological or physical health can interact to influence voting behavior, a study by Bor (2017)(57) found that counties which experienced decreased life expectancy between 1980 and 2014 showed greater support for Trump in the 2016 election, and were more likely to switch from supporting Obama in 2008 to Trump in 2016. The results presented here compliment these findings and provide more evidence linking social isolation with populism. Intriguingly, recent research also suggests that nihilistic beliefs and a measure that the authors call a 'need for chaos' positively correlates with loneliness and support for both Trump and Sanders(58).

There are several caveats worth noting. First, our measure of social capital is limited. For instance, although the social capital index we use includes measures such as per capita bowling alleys, community centers, and churches, these institutions may have been replaced by other unknown or poorly understood institutions such as social media. It is important to note, however, that the rise of social media, rather than helping to replace traditional institutions that generated social capital, may actually be more likely to exacerbate our tribal 'us vs them' tendencies and reduce it (59). Measures of suicides, alcohol abuse, and drug overdoses are also valuable indicators of the overall health of a society and may be considered a proxy for understanding the status of social networks. Moreover, because the CDC records the cause of death for every person in the United States each year, mortality data do not depend on dubious self-reports. In this way, we were able to avoid the possible pitfalls of missing data on social capital. Second, we do not address voter turnout and it is possible that voters who are more affected by deteriorating social networks are simply more energized and, therefore more likely to vote. However, if true, this would still suggest that social factors play an important role in energizing voters which of course affects election results. It is also not entirely clear how the social, demographic and economic factors we entered into these models are related. For example, if economic factors, such as decreasing household income, increase the risk of suicide, our models will fail to capture the indirect effects of income on voting. In other words, with our current models we are only able to model the direct effect of our predictors and may therefore may fail to capture the indirect ones coming, for example, via the deterioration of social networks, which would lead to an underestimation of the influence of these predictors. However, this would also be true if, social factors influenced economic ones (e.g. a decline in social capital caused businesses to leave certain areas which in turn led to an increase in unemployment rates). Finally the factors which benefit populist candidates are likely to affect populists on each end of the political spectrum differently. For example, factors linked to economic decline may disproportionately favor populists on the right(60) and our results support this conclusion (see Table 1). Furthermore increasing political polarization may also play a role in increasing support for populist candidates by disrupting social networks (see Supplementary materials text: The role of polarization and differences between populists on the left and the right).

Our results show that an increase in suicides, alcoholrelated deaths, and a reduction in overall social capital predict support for populist candidates in the 2016 presidential election. This study provides evidence for the social isolation hypothesis which contends that the disruption of social networks play a central role in generating populist discontent. Populist movements frequently reveal deeply rooted fissures in society that are not being addressed by traditional politics. Our results indicate that a widespread decay of social capital and the degeneration of social networks in the United States may play a greater role in underwriting populist outrage than either economic or demographic changes. Future studies on the causes of political change would benefit from a closer look into the effects that changes in social capital and general public health have on voting behavior. These results suggest that focusing on public health issues - physical, mental health, and addiction treatment- may be just as important in adapting to globalization as other well-known factors, like job training, and may also have significant political consequences.

\section{Materials and Methods}

Data acquisition and description. General 2016 presidential election data was obtained from the U.S. Election Atlas, an online database that compiles statewide data from the Secretary of State(61) and Open data Soft (62). Results from the GOP and DNC primaries were obtained from(63). Data from Alaska were excluded because Alaska reports voting results by district which cannot be mapped to counties. Mortality data on suicides (CDC codes: UO3, X60-84 and Y87.0), alcohol-induced deaths (codes: A1 and A9), 
and unintentional drug poisoning (overdose) (code: D1) were obtained from the Center for Disease Control (CDC) Wonder database (64). The Social Capital Index for the years 2005 and 2014 was obtained from the Pennsylvania State University Northeast Regional Center for Rural Development website(65). This index was created using the first eigenvector of the principal component analysis for the following four factors: 1) the aggregate of the number of religious, civic, business, political, professional and labor organizations, bowling alleys, fitness centers, golf courses, and sports teams per 1,000 individuals, 2) voter turnout, 3 ) census response rate, and 4) the number of non-profit organizations in an area. These four factors are combined and standardized to have a mean of zero and a standard deviation of one. This index has been shown to support hypotheses drawn from the literature on social capital and is strongly correlated with previous findings(66). All other variables, including the percentage of the population that is white, foreign born or has a bachelor's degree, the median household income, male and female unemployment rates and populations were obtained directly from the Census Bureau's American Community Survey (ACS) - a nationally representative survey of Americans - using the 'tidycensus' package in $\mathrm{R}(67)$. This resulted in a dataset with complete cases for 3,110 counties [130,261,968 total votes] for the Clinton Trump general election, 2,848 counties [31,181,493 total votes] in the Democratic primary and 2,739 counties $[16,681,950]$ in the Republican primary.

Pre-registration. All methods and statistical analyses were pre-registered on May 23, 2018, prior to our analysis(42). The predictors, outcomes, model selection criteria, and statistical methods outlined below are similar to those identified in the Open Science Framework (OSF) pre-registration. The main difference between our predictions and those we pre-registered is the addition of predictions for the results of the GOP primary using data which we obtained after we had pre-registered. All data used for this study and code for these analyses have been uploaded to a publicly available repository on Github. (68)

Imputing suppressed data from the CDC. To protect against the potential disclosure of anonymized personal health data, the CDC (64) suppresses any counts for causes of death that have less than ten observations. In order to obtain these missing values from counties with suppressed data (i.e. $<10$ observations), we extracted the cause of death counts for all available years (1999-2016) and then subtracted from these total multi year mortality counts the count for the year we wanted (e.g. 2016 or 2008). This first step reduced the number of suppressed rows by approximately $85 \%$ for all three causes of death. Next we inferred the values of the remaining ( $7 \%$ ) of suppressed rows by 1 ) summing the populations of all counties which still had missing counts for each state and dividing the population of each suppressed county by this total in order to generate a missing population ratio for each state, 2) summing the known counts for all counties within each state and subtracting this from the state total to obtain a total number of missing deaths for each state and 3) multiplying the missing deaths by the missing population. In effect we were able to take advantage of several aspects of the WONDER website (i.e. multi year totals, county level population and data grouped by state) to impute all missing mortality counts for suicides, alcoholrelated death, and drug overdoses for counties in the United States. The $\mathrm{R}$ code used to impute these missing data can be found on Github(68).

Dependent variables. The dependent variables in this study are individual vote counts from the 2016 general election and the democratic and republican primaries aggregated by county. Three models were generated, which modeled each of the following binomial outcome variables: 1) The number of votes received by Trump (success) vs Clinton (failure) in the 2016 general presidential election, 2) number of votes received by Sanders (success) vs Clinton (failure) in the 2016 DNC primary, and 3) the number of votes received by Trump (success) vs Kasich (failure) in the 2016 GOP Primary. Kasich was used in comparison to Trump in the GOP primary because he was the most traditional of the Republican candidates who stayed in the race all the way through the convention which means that all states had the opportunity to vote for him.

Predictors . The main predictors of interest - differences in per capita (per 100k individuals) deaths due to alcohol, drug overdoses, suicides (2008 to 2016), and the social capital index (2005 to 2014) - were designed to measure social changes in the aftermath of the 2008 financial crisis. Variables used to asses basic demographic changes were county level differences in the percent of residents who were white, the percent who were foreign born, and the population size (logged) between 2010 and 2016. Economicvariables included were changes in the male unemployment rate, the female unemployment rate, median household income (logged) and, percent of residents with a bachelor's degree between 2010 and 2016. Finally state was entered as a random effect (i.e., random intercepts) into all the models. Although selecting which predictors to include in models usually has a somewhat arbitrary component, the factors that we selected were ones that previous research has shown to have had strong effects on results of the 2016 elections(69). Our primary aim was to examine how changes in the predictors leading up to the 2016 election (e.g. change in per capita suicides between 2008 to 2016) were associated with support for populist candidates. Therefore we did not enter the fixed 2016 values of these variables into our models (e.g. per capita suicides in 2016), because it is highly likely that the 2016 values are causally affected by the degree of their change from the year 2008 (see Table S5 for variance inflation factors (VIF) when including fixed (2016) rates into each of our models). So despite the fact that the fixed values would also have had some explanatory power to our models ability to predict support for populism in the same year, they serve as the mediators of the changes in these variables and would therefore have biased the regression estimates (i.e. we would have estimated their direct effects instead of total effects)(70). Male and female unemployment rate were entered separately into the models to help parse the effects of sex biased economic distress on voting patterns.

Categorizing counties as populist. To analyze the impact of our predictors on the likelihood of voting for a populist can- 
didate, we created a subset of 198 counties (out of a total of 3164 for which we had complete data) which we classified as populist (see Supplementary Materials: Figure S1-top panel). The following criteria had to be met: First, more than $50 \%$ of the votes in the county had to have been for both populist candidates - Trump in the general election and Sanders in the DNC primary, and second, the majority of the county had to have voted for Obama vs McCain in the 2008 presidential election. In other words, these were counties that had flipped from Obama to Trump between 2008 and 2016 and had also voted for Sanders. Exclusion of counties which had voted for McCain in 2008 (a more traditional Republican candidate) was done to eliminate counties that were just Republican counties, regardless of whether Trump was the candidate, from being classified as being populist. This is only a problem, however, for voting patterns in the general election, and there was no similar expectation that voting for Sanders counties would be biased by party affiliation in the DNC primary, because almost all of the voters are expected to have been Democrats. For counties to be categorized as 'traditional' (see Supplementary Materials: Figure S1-bottom panel) fewer than 50\% of the votes in the county had to have been for Trump in the general election and fewer than $50 \%$ for Sanders in the DNC primary.

Statistical Analysis and model estimation. We used Bayesian inference for all statistical analyses. In a Bayesian framework, each model conditions data on prior probability distributions and uses Monte-Carlo sampling methods to generate posterior distributions for the parameters. The priors are the initial probabilities for each possible value of each parameter. This type of analysis allows us to compare posterior distributions across predictors without relying on specific post-hoc tests(71), and averts the need to adjust for multiple comparisons(72). We are also better able to visualize and interpret differences between parameter estimates relative to a specific value by reporting and displaying the entire posterior distribution for each predictor and showing the highest density intervals (HDI) which displays the most credible values for each parameter estimate. We specified broad but weakly regularizing priors to tamp the effects of extreme values: normal distributions centered on null hypothesized isometric slopes for all continuously varying covariates, and Cauchy distributions with a shape parameter of 2.5 for standard deviations. For the random effect of state we used a gamma distributed prior covariance matrix with shape and scale parameters equal to one. Models were run with four replicate chains for 10,000 MCMC iterations with a $20 \%$ warm up. All statistical analyses were performed in $\mathrm{R}$ version 3.5.1. Bayesian inference was carried out using the rstan package for $\mathrm{R}$ (version 2.14.1; https://cran.r-project.org/web/packages/ rstan/index.html), an interface to Stan which uses a Hamiltonian Monte Carlo No-U-Turn sampler(73)(for trace plots for all fixed effects entered into these models see Supplementary Materials: Figures $4 \mathrm{a}-\mathrm{c}$ ). Here we assume that $95 \%$ highest density intervals which do not include zero are evidence that the parameter value is credibly different from the baseline. Posterior predictive checks were used to check the model fit by simulating replicated data under the fitted model and then comparing these to the observed data. They are used to look for systematic discrepancies between real and simulated data by comparing the distribution of random draws of new data generated by the model to the observed data(71). Scatter plot and correlations between model predictions and observed data for each of the 3 models are shown in Figures S3a-S3c (Clinton vs Trump model $(r=0.55)$; Sanders vs Clinton $\mathrm{r}=0.79$; Trump vs Kasich model $(\mathrm{r}=0.85)$. These models were all run on the Taito supercluster("CSC - Computing and Software," n.d.). The R code for all of these models is stored on github(68).

We used a generalized linear mixed-effects model (GLMM) with a logit link function to model the proportion of votes received by either Trump or Sanders in the Democratic primary or the general election using the stan_glmer function from the 'rstanarm' package in $\mathrm{R}$ studio version 3.5 .

$$
\begin{gathered}
n_{\text {populist }, i} \sim \operatorname{Binomial}\left(n_{i}, p_{i}\right) \\
\operatorname{logit}\left(p_{i}\right)=\alpha+\beta_{p} \text { Predictor } 1+\ldots
\end{gathered}
$$

The logit link function maps the probability distribution that in this case is constrained to be either a 1 [vote for populist] or a 0 [vote for non populist] onto a linear model that can take any values. Because the number of trials (i.e. vote counts) were not constant and varied greatly across counties (e.g. Trump won $48.6 \%$ of the total vote but $83.6 \%$ of the counties in the general election), we used an aggregated binomial logistic regression. An aggregated binomial treats each individual vote [populist $=1$, non-populist $=0$ ] as a separate observation and obviates the need to weigh the data by the number of votes in each county (see $\mathrm{R}$ code for exact specifications for all 3 models). For mathematical formulas for each of the 3 models (see Supplementary Materials: Mathematical models).

DATA ARCHIVAL. All data and code used in these analyses can be found on a public repository on Github(68).

ACKNOWLEDGMENTS. We would like to thank Mamaroneck High School Open Science Research teachers Guido Garbarino and Alejandro Victoroa for their support and Dave O'Brien and Karthik Panchnathan for helping to edit the manuscript.

1. J Bowlby, Attachment. attachment and loss: Vol. 1. loss (1969).

2. P Norris, R Inglehart, Cultural Backlash and the Rise of Populism: Trump, Brexit, and Authoritarian Populism. (Cambridge University Press), (2019).

3. H Enten, Hillary clinton is the george w. bush of 2016 (https://fivethirtyeight.com/features/ hillary-clinton-is-the-george-w-bush-of-2016/) (2015) Accessed: 2018-11-12.

4. D Smith, Trump and sanders lead two-headed insurgency against establishment. The Guard. (2016).

5. T Frank, What's the Matter with Kansas?: How Conservatives Won the Heart of America. (Henry Holt and Company), (2007).

6. G Lakoff, The political mind. New York: Viking (2008).

7. RF Inglehart, P Norris, Trump, brexit, and the rise of populism: Economic have-nots and cultural backlash. (2016).

8. T Campbell, Populism and its discontents: Populism on the american left and right during the 2016 election cycle. (2017).

9. JM Berry, C Wilcox, The interest group society. (Routledge), (2018).

10. H Allcott, M Gentzkow, Social media and fake news in the 2016 election. J. Econ. Perspect. 31, 211-236 (2017)

11. KJ Cramer, The Politics of Resentment: Rural Consciousness in Wisconsin and the Rise of Scott Walker. (University of Chicago Press), (2016).

12. MJ Jensen, HP Bang, Populism and democratic connectivism: The trump and sanders nomination campaigns. J. Polit. Mark., null-null (2017).

13. C Mudde, CR Kaltwasser, Populism: A Very Short Introduction. (Oxford University Press), (2017).

14. K Abts, S Rummens, Populism versus democracy. Polit. Stud. 55, 405-424 (2007).

15. T Bale, $S$ van Kessel, $P$ Taggart, Thrown around with abandon? popular understandings of populism as conveyed by the print media: A UK case study. Acta Polit 46, 111-131 (2011).

16. MJ Hetherington American Political Science Review, 1999, The effect of political trust on the presidential vote, 1968-96. cambridge.org (1999). 
7. M Hirsh, Why trump and sanders were inevitable. POLITICO Mag. Febr. 28 (2016).

18. P Stankov, The political economy of populism: An empirical investigation. Comp. Econ. Stud. 60, 230-253 (2018).

19. R Dalio, A Template For Understanding BIG DEBT CRISES. (Bridgewater Associates), (2018).

20. A Sufu, Why you should blame the financial crisis for political polarization and the rise of trump - evonomics (https://evonomics.com/blame-financial-crisis-politics-rise-of-trump/) (2016) Accessed: 2018-9-14.

21. R Inglehart, Modernization and Postmodernization: Cultural, Economic, and Political Change in 43 Societies. (Princeton University Press), (1997).

22. DC Mutz, Status threat, not economic hardship, explains the 2016 presidential vote. Proc. Natl. Acad. Sci. U. S. A. 115, E4330-E4339 (2018)

23. P Krugman, Opinion. The New York Times (2018).

24. F Fukuyama, Against identity politics: The new tribalism and the crisis of democracy. Foreign Aff. 97, 90 (2018).

25. R Wuthnow, The Left Behind: Decline and Rage in Rural America. (Princeton University Press), (2018).

26. JB Silk, The adaptive value of sociality in mammalian groups. Philos. Transactions Royal Soc. B: Biol. Sci. 362, 539-559 (2007).

27. JP Henrich, Foundations of human sociality: Economic experiments and ethnographic evidence from fifteen small-scale societies. (2004).

28. RD Putnam, E pluribus unum: Diversity and community in the twenty-first century the 2006 johan skytte prize lecture. Scan. Polit. Stud. 30 (2007).

29. BK Alexander, RB Coambs, PF Hadaway, The effect of housing and gender on morphine self-administration in rats. Psychopharmacology 58, 175-179 (1978).

30. A Case, A Deaton, Mortality and morbidity in the 21 st century. Brookings Pap. Econ. Act., 23-24 (2017).

31. E Durkheim, Suicide: a study in sociology [1897]. Transl. by JA Spaulding G. Simpson (Glencoe, Illinois: The Free. Press. 1951) (1897).

32. W Kornhauser, Politics of mass society. (Routledge) Vol. 49, (2013).

33. R Putnam, Bowling alone: The collapse and revival of American community. (Simon and Schuster, New York), (2000).

34. GSS data explorer | NORC at the university of chicago (https://gssdataexplorer.norc.org/ variables/848/vshow) (2019) Accessed: 2019-4-29.

35. N Newman, R Fletcher, A Kalogeropoulos, DA Levy, RK Nielsen, Reuters institute digital news report 2017. (2017).

36. A Hjern, F Lindblad, B Vinnerljung, Suicide, psychiatric illness, and social maladjustment in intercountry adoptees in sweden: a cohort study. Lancet 360, 443-448 (2002).

37. AA van Raalte, I Sasson, P Martikainen, The case for monitoring life-span inequality. Science 362, 1002-1004 (2018).

38. M Heron, Deaths: Leading causes for 2016. Natl. Vital Stat. Rep. 67, 1-77 (2018).

39. A Case, A Deaton, Rising morbidity and mortality in midlife among white non-hispanic americans in the 21st century. Proc. Natl. Acad. Sci. U. S. A. 112, 15078-15083 (2015).

40. D Kahneman, A Tversky, Prospect theory: An analysis of decision under risk in Handbook of the Fundamentals of Financial Decision Making, World Scientific Handbook in Financial Economics Series. (WORLD SCIENTIFIC) Vol. 4, pp. 99-127 (2012).

41. B Moffitt, S Tormey, Rethinking populism: Politics, mediatisation and political style. Polit. studies 62, 381-397 (2014).

42. Lynch, R And Lynch,, Open science framework (https://osf.io/z7328/) (2018).

43. R Fischer, TL Milfont, Standardization in psychological research. Int. J. psychological research 3, 88-96 (2010).

44. ME Rice, GT Harris, Comparing effect sizes in follow-up studies: Roc area, cohen's d, and r. Law human behavior 29, 615-620 (2005).

45. PJ Flores, Addiction as an Attachment Disorder. (Jason Aronson), (2004).

46. MF Grunebaum, et al., Attachment and social adjustment: relationships to suicide attempt and major depressive episode in a prospective study. J. Affect. Disord. 123, 123-130 (2010).

47. B Alexander, The Globalization of Addiction: A Study in Poverty of the Spirit. (Oxford University Press), (2010).

48. P Fonagy, Attachment and borderline personality disorder. J. Am. Psychoanal. Assoc. 48, 1129-46; discussion 1175-87 (2000).

49. LM Rossen, D Khan, M Warner, Hot spots in mortality from drug poisoning in the united states, 2007-2009. Heal. \& place 26, 14-20 (2014).

50. N Dasgupta, MJ Funk, JS Brownstein, Comparing unintentional opioid poisoning mortality in metropolitan and non-metropolitan counties, united states, 1999-2003 in Geography and drug addiction. (Springer), pp. 175-192 (2008).

51. L Hester, $X$ Shi, N Morden, Characterizing the geographic variation and risk factors of fatal prescription opioid poisoning in new hampshire, 2003-2007. Annals GIS 18, 99-108 (2012).

52. S Abuse, Mental health services administration.(2014). Results from 20011 (2010).

53. D Oesch, Explaining workers' support for right-wing populist parties in western europe: Evidence from austria, belgium, france, norway, and switzerland. Int. Polit. Sci. Rev. 29, 349-373 (2008).

54. S Verick, Who is hit hardest during a financial crisis? the vulnerability of young men and women to unemployment in an economic downturn. (2009).

55. W Davies, Why we stopped trusting elites. The Guard. (2018).

56. D Kahneman, Prospect theory: An analysis of decisions under risk. Econometrica 47, 278 (1979).

57. J Bor, Diverging life expectancies and voting patterns in the 2016 US presidential election. Am. J. Public Heal. 107, 1560-1562 (2017).

58. MB Petersen, M Osmundsen, K Arceneaux, A "need for chaos" and the sharing of hostile political rumors in advanced democracies. (2018).

59. R McDermott, PK Hatemi, To go forward, we must look back: The importance of evolutionary psychology for understanding modern politics. Evol. Psychol. 16, 1474704918764506
(2018).

60. J Austin, Midterms showed that midwestern economic performance could decide 2020 race. Brookings Press. (2019).

61. D Leip, David leip's election atlas (https://uselectionatlas.org/) (year?) Accessed: 2018-3-30

62. OD Soft, Presidential election 2016 data (https://data.opendatasoft.com/explore/dataset/ usa-2016-presidential-election-by-county/40public/export/?disjunctive.state) (year?)

63. B Hamner, 2016-us-election (year?).

64. CDC, Center for disease control wonder (https://wonder.cdc.gov/controller/datarequest/D77; jsessionid=010C09A84F0324F3416B9419D25A890D) (year?) Accessed: 2018-9-NA

65. Penn State, Social capital variables spreadsheet (https://aese.psu.edu/nercrd/community/social-capital-resources/social-capitalvariables-for-2014/social-capital-variables-spreadsheet-for-2014/view) (year?) Accessed: 2018-NA-NA.

66. A Rupasingha, SJ Goetz, D Freshwater, The production of social capital in us counties. The journal socio-economics 35, 83-101 (2006).

67. American community survey, Census bureau (https://factfinder.census.gov/faces/nav/jsf/ pages/index.xhtml) (year?) Accessed: 2018-8-30

68. R Lynch, Populism-Study (https://github.com/robertlynch66/Populism-study) (year?) Accessed: 2018-11-13.

69. SJ Goetz, M Davlasheridze, Y Han, DA Fleming-Muñoz, Explaining the 2016 Vote for President Trump across U.S. Counties. (2018).

70. F Elwert, Graphical causal models in Handbook of causal analysis for social research. (Springer), pp. 245-273 (2013).

71. R McElreath, Statistical rethinking. texts in statistical science (2015).

72. A Gelman, J Hill, M Yajima, Why we (usually) don't have to worry about multiple comparisons. J. Res. Educ. Eff. 5, 189-211 (2012).

73. MD Hoffman, A Gelman, The no-u-turn sampler: adaptively setting path lengths in hamiltonian monte carlo. J. Mach. Learn. Res. 15, 1593-1623 (2014). 


\title{
Support for populist candidates in the 2016
}

\section{presidential elections predicted by declining social capital and an increase in suicides}

\author{
Lynch, $\mathbf{R}^{1, *}$, Lynch, $\mathbf{N}^{2}$, Chapman, $\mathbf{S}^{1}$, Briga, $\mathbf{M}^{1}$, Lynch, $\mathbf{E}^{1}$, ANd Helle, $\mathbf{S}^{1}$ \\ ${ }^{1}$ University of Turku, Turku, Finland \\ robertflynch@gmail.com \\ ${ }^{2}$ Mamaroneck High School, Mamaroneck, NY
}

Compiled May 23, 2019

\section{SUPPLEMENTARY TEXT}

\section{Prospect theory}

Prospect Theory is a theory in cognitive psychology that describes how humans choose between alternatives when outcomes are uncertain. It states that individuals do not make decisions solely on the desired outcome, but, rather, are expected to rely on heuristics that depend on how they value losses vs. gains[1]. For example, if there is a high probability of gains (e.g. a $95 \%$ chance to win $\$ 10,000$ ) individuals are expected to be more risk averse, more fearful of losing these profits and will be more likely to lock in their gains, whereas if there is a high probability of losses (e.g. 95\% chance to lose $\$ 10,000$ ) they are expected to be more tolerant of risk and will be more likely to take a chance hoping to avoid locking in the loss. Overall, Prospect theory predicts that voters tolerance for risk will increase when they are faced with potential or actual losses[2]. Therefore when conditions are stable, voters are expected to be more risk-averse which should benefit political incumbents, but when conditions are uncertain, voters are expected to be more risk-tolerant which is more likely to benefit the challenger.

\section{The role of polarization and differences between populists on the left and the right}

Political polarization in the United States is higher than at any time since the Civil War and a pew research poll showed that Americans view conflicts between Republicans and Democrats as more severe than between any other groups they measured (e.g. blacks vs whites, urban vs rural, rich vs poor and old vs young) [3]. Therefore the results of elections between candidates from the same political party (e.g. Clinton vs Sanders or Trump vs Kasich) and those between parties (e.g Clinton vs Trump) must be interpreted differently. This is particularly true in a highly polarized electorate and polarization itself may even play a role in increasing support for populist candidates by disrupting social networks. These effects can be exacerbated by many of the same factors that are seen to increase loneliness and decrease mental health, including rapid demographic changes [4], stagnation in median wages[5], the 'echo chamber' of social media[6], the increasing partisanship of cable television and other media outlets [7], and by the erosion of confidence in social mobility[8]. Many of these same factors can strain relationships with family members and a 2018 study showed that Thanksgiving dinners attended by residents from opposing-party precincts were significantly shorter than those attended by residents of same party precincts.[9].

Regardless of whether polarization itself causes populist support to increase, it is almost certain to affect populists on each end of the political spectrum differently. For example, factors linked to social or economic decline may disproportionately favor populists on the right. One study showed that residents of congressional districts which voted Democrat in 2016 but then switched to vote for a Republican in the 2018 midterm elections had lower incomes and were less educated than statewide medians, while the opposite was true (i.e. higher incomes and more educated) in districts that moved from Republican to Democrat[10]. Economically struggling districts, particularly those in the Midwest, were also more likely to vote for Trump in 2016[11]. Evidence from elsewhere in the world also provides support for economy-driven swings to the right: support 
for Brexit was higher among British voters who were most hurt by globalization and austerity measures in the aftermath of the 2008 recession[12,13], and job losses and austerity measures in Greece were linked with decreased generalized solidarity, increasing in-group bias, and increasing support for right-wing populist candidates[14].

\section{Mathematical models}

Here are the mathematical models (see Github repository[15] and supplementary materials for R code):

\section{[Model 1]}

$$
\begin{aligned}
& \text { Trump_votes }_{i} \sim \operatorname{Binomial}\left(\text { Total_votes }(\text { Trump }+ \text { Clinton })_{i}, \text { prob }_{i}\right) \\
& \operatorname{logit}_{\left(\text {prob }_{i}\right)}=\alpha+\beta \Delta \text { suicides }_{i}+ \\
& \beta \Delta \text { drug_deaths }_{i}+\beta \Delta \text { alcohol_deaths } s_{i}+ \\
& \beta \Delta \text { social_capital }_{i}+\beta \Delta \text { foreign_born }_{i}+ \\
& \beta \Delta \text { percent_white }{ }_{i}+\beta \Delta \log (\text { population })_{i}+ \\
& \beta \Delta \text { male_unemployment } t_{i}+\beta \Delta \text { female_unemployment }_{i}+ \\
& \beta \Delta \text { household_income }_{i}+\beta \Delta \text { bachelors_degree }_{i}
\end{aligned}
$$

Model 1 used changes in per capita suicides, drug overdoses, deaths due to alcohol, social capital, percent foreign born, percent white, log of the population, percent of male unemployment, percent of female unemployment, household income and percent with a bachelors degree to predict the percentage of the votes received by Sanders in comparison to Clinton in the 2016 Democratic primary (see Table S1 for parameter estimates and $97.5 \%$ Credibility intervals).

\section{[Model 2]}

$$
\begin{aligned}
& \text { Sanders_votes }_{i} \sim \operatorname{Binomial}\left(\text { Total_votes }(\text { Sanders }+ \text { Clinton })_{i}, \text { prob }_{i}\right) \\
& \operatorname{logit}_{\left(\text {prob }_{i}\right)}=\alpha+\beta \Delta \text { suicides }_{i}+ \\
& \beta \Delta \text { drug_deaths } s_{i}+\beta \Delta a l c o h o l \_d e a t h s_{i}+ \\
& \beta \Delta \text { social_capital }_{i}+\beta \Delta \text { foreign_born }_{i}+ \\
& \beta \Delta \text { percent_white }{ }_{i}+\beta \Delta \log (\text { population })_{i}+ \\
& \beta \Delta \text { male_unemployment }{ }_{i}+\beta \Delta \text { female_unemployment }_{i}+ \\
& \beta \Delta \text { household_income }_{i}+\beta \Delta \text { bachelors_degree }_{i}
\end{aligned}
$$

Model 2 used these same factors(see Model 1) to predict the percentage of the votes received by Sanders in comparison to Clinton in the 2016 Democratic primary (see Table S2 for parameter estimates and 97.5\% Credibility intervals).

\section{[Model 3]}

$$
\begin{aligned}
& \text { Trump_primary_votes }_{i} \sim \operatorname{Binomial}\left(\text { Total_votes }(\text { Kasich }+\operatorname{Trump})_{i}, \operatorname{prob}_{i}\right) \\
& \operatorname{logit}_{\left(\text {prob }_{i}\right)}=\alpha+\beta \Delta \text { suicides }_{i}+ \\
& \beta \Delta d r u g \_d e a t h s_{i}+\beta \Delta a l c o h o l \_d e a t h s_{i}+ \\
& \beta \Delta \text { social_capital }_{i}+\beta \Delta \text { foreign_born }_{i}+ \\
& \beta \Delta \text { percent_white }{ }_{i}+\beta \Delta \log (\text { population })_{i}+ \\
& \beta \Delta \text { male_unemployment }{ }_{i}+\beta \Delta \text { female_unemployment }_{i}+ \\
& \beta \Delta \text { household_income }_{i}+\beta \Delta \text { bachelors_degree }_{i}
\end{aligned}
$$


Model 3 used these same factors (see Model 1) to predict the percentage of the vote received by Trump in comparison to Kasich in the 2016 Republican primary (see Table S3 for parameter estimates and 97.5\% Credibility intervals).

\section{REFERENCES}

1. D. Kahneman, "Prospect theory: An analysis of decisions under risk," Econometrica 47, 278 (1979).

2. G. A. Quattrone and A. Tversky, "Contrasting rational and psychological analyses of political choice," Am. Polit. Sci. Rev. 82, 719-736 (1988).

3. " $86 \%$ of americans say conflicts between democrats, republicans are strong," https://www.pewresearch.org/ fact-tank/2017/12/19/far-more-americans-say-there-are-strong-conflicts-between-partisans-than-between-other-groupsAccessed: 2019-5-20.

4. $\quad$ L. Mason, Uncivil agreement: How politics became our identity (University of Chicago Press, 2018).

5. G. C. Layman, T. M. Carsey, and J. M. Horowitz, "PARTY POLARIZATION IN AMERICAN POLITICS: Characteristics, causes, and consequences," Annu. Rev. Polit. Sci. 9, 83-110 (2006).

6. H. Allcott and M. Gentzkow, "Social media and fake news in the 2016 election," J. Econ. Perspect. 31, 211-236 (2017).

7. M. Gentzkow, "Polarization in 2016," Toulouse Netw. Inf. Technol. white paper (2016).

8. R. D. Putnam, "Our kids," The Am. dream crisis. New York: Simon \& Schuster (2015).

9. M. K. Chen and R. Rohla, "The effect of partisanship and political advertising on close family ties," Science 360, 1020-1024 (2018).

10. J. Austin, "Midterms showed that midwestern economic performance could decide 2020 race," Brookings Press. (2019).

11. J. Austin, "A tale of two rust belts: Diverging economic paths shaping community politics," Brookings Press. (2017).

12. T. Fetzer, "Did austerity cause brexit?" (2018).

13. E. Alabrese, S. O. Becker, T. Fetzer, and D. Novy, "Who voted for brexit? individual and regional data combined," Eur. J. Polit. Econ. (2018).

14. N. Sambanis, A. Schultz, and E. Nikolova, "Measuring the effects of economic austerity on pro-sociality: Evidence from greece," Available at SSRN 3239925 (2018).

15. R. Lynch, "Populism-Study," https://github.com/robertlynch66/Populism-study. Accessed: 2018-11-13.

16. T. R. Levine and C. R. Hullett, "Eta squared, partial eta squared, and misreporting of effect size in communication research," Hum. Commun. Res. 28, 612-625 (2002).

17. P. Cohen, J. Cohen, L. S. Aiken, and S. G. West, "The problem of units and the circumstance for pomp," Multivar. behavioral research 34, 315-346 (1999). 


\section{SUPPLEMENTARY TABLES AND FIGURES}

Trump Clinton 2016 General election [Model $R^{2}=0.40$ ]

\begin{tabular}{|c|c|c|c|}
\hline PREDICTOR & Mean & $2.5 \%$ & $97.5 \%$ \\
\hline \multicolumn{4}{|l|}{ Social change } \\
\hline Increase in suicides & 0.013 & 0.013 & 0.013 \\
\hline Increase in drug overdoses & -0.005 & -0.005 & -0.005 \\
\hline Increase in alcohol deaths & 0.008 & 0.008 & 0.008 \\
\hline Increase in social capital ${ }^{\star}$ & -0.190 & -0.190 & -0.189 \\
\hline \multicolumn{4}{|l|}{ Demographic change } \\
\hline Increase in percent foreign born & -1.80 & -1.85 & -1.75 \\
\hline Increase in percent white & 14.42 & 14.40 & 14.46 \\
\hline Increase in population & -4.05 & -4.06 & -4.03 \\
\hline \multicolumn{4}{|l|}{ Economic change } \\
\hline Increase in male unemployment & -17.47 & -17.60 & -17.34 \\
\hline Increase in female unemployment & 27.28 & 27.01 & 27.55 \\
\hline Increase in median household income & 0.061 & 0.052 & 0.070 \\
\hline Increase in percent with bachelors degree & -20.15 & -20.20 & -20.11 \\
\hline
\end{tabular}

Table S1: Parameter estimates for factors affecting the number of votes that Trump received in comparison to Clinton in 2016. All changes (i.e. increases) were calculated as the difference between 2016 and 2008 except social capital which was calculated as the difference between 2014 and $2005^{\star}$. Suicides, drug overdoses and deaths due to alcohol are entered as rates per 100,000 individuals and were obtained from the Center for Disease control. Social capital is centered at zero and a one point difference in either direction represents one standard deviation. Population and median household income were both logged. The fixed variables were estimated using data from 2016 except social capital which used data from 2014. Percent with a bachelors degree, percent foreign born, household income, unemployment rates, percent white, population are estimates from the Census Bureau American Community Surveys (ACS) from 2008 and 2016. 
Sanders Clinton 2016 DNC Primary [Model $R^{2}=0.66$ ]

\begin{tabular}{|c|c|c|c|}
\hline PREDICTOR & Mean & $2.5 \%$ & $97.5 \%$ \\
\hline \multicolumn{4}{|l|}{ Social change [2008-2016] } \\
\hline Increase in suicides & 0.006 & 0.006 & 0.007 \\
\hline Increase in drug overdoses & -0.001 & -0.001 & -0.001 \\
\hline Increase in alcohol deaths & 0.006 & 0.006 & 0.006 \\
\hline Increase in social capital $^{\star}$ & -0.08 & -0.08 & -0.08 \\
\hline \multicolumn{4}{|l|}{ Demographic change [2008-2016] } \\
\hline Increase in percent foreign born & -4.48 & -4.58 & -4.37 \\
\hline Increase in percent white & 3.62 & 3.55 & 3.69 \\
\hline Increase in population & 1.53 & 1.49 & 1.60 \\
\hline \multicolumn{4}{|l|}{ Economic change [2008-2016] } \\
\hline Increase in male unemployment & -6.63 & -6.93 & -6.34 \\
\hline Increase in female unemployment & 1.72 & 1.11 & 2.33 \\
\hline Increase in median household income & 0.589 & 0.569 & 0.608 \\
\hline Increase in percent with bachelors degree & -3.18 & -3.27 & -3.08 \\
\hline
\end{tabular}

Table S2: Parameter estimates for factors affecting the number of votes that Sanders received in comparison to Clinton in the 2016 Democratic primary. All changes (i.e. increases) were calculated as the difference between 2016 and 2008 except social capital which was calculated as the difference between 2014 and 2005`. Suicides, drug overdoses and deaths due to alcohol are entered as rates per 100,000 individuals and were obtained from the Center for Disease control. Social capital is centered at zero and a one point difference in either direction represents one standard deviation. Population and median household income were both logged. Percent with a bachelors degree, percent foreign born, household income, unemployment rates, percent white, population are estimates from the Census Bureau American Community Surveys (ACS) from 2008 and 2016. 
Trump Kasich 2016 GOP Primary [Model $R^{2}=0.76$ ]

\begin{tabular}{|c|c|c|c|}
\hline PREDICTOR & Mean & $2.5 \%$ & $97.5 \%$ \\
\hline \multicolumn{4}{|l|}{ Social change [2008-2016] } \\
\hline Increase in suicides & 0.002 & 0.002 & 0.002 \\
\hline Increase in drug overdoses & 0.002 & 0.002 & 0.002 \\
\hline Increase in alcohol deaths & 0.004 & 0.003 & 0.004 \\
\hline Increase in social capital $^{\star}$ & -0.073 & -0.075 & -0.071 \\
\hline \multicolumn{4}{|l|}{ Demographic change [2008-2016] } \\
\hline Increase in percent foreign born & -3.01 & -3.21 & -2.82 \\
\hline Increase in percent white & 6.17 & 6.07 & 6.27 \\
\hline Increase in population & -5.89 & -5.95 & -5.84 \\
\hline \multicolumn{4}{|l|}{ Economic change [2008-2016] } \\
\hline Increase in male unemployment & -7.50 & -7.91 & -7.08 \\
\hline Increase in female unemployment & 10.62 & 9.56 & 11.65 \\
\hline Increase in median household income & -0.083 & -0.11 & -0.05 \\
\hline Increase in percent with bachelors degree & -11.17 & -11.31 & -11.02 \\
\hline
\end{tabular}

Table S3: Parameter estimates for factors affecting the number of votes that Trump received in comparison to Kasich in 2016. All changes (i.e. increases) were calculated as the difference between 2016 and 2008 except social capital which was calculated as the difference between 2014 and 2005`. Suicides, drug overdoses and deaths due to alcohol are entered as rates per 100,000 individuals and were obtained from the Center for Disease control. Social capital is centered at zero and a one point difference in either direction represents one standard deviation. Population and median household income were both logged. Percent with a bachelors degree, percent foreign born, household income, unemployment rates, percent white, population are estimates from the Census Bureau American Community Surveys (ACS) from 2008 and 2016. 


\begin{tabular}{|c|c|c|c|c|c|c|}
\hline & Correlation & S.E. & p-value & VIF-Trump Clinton & VIF-Sanders Clinton & VIF-Trump Kasich \\
\hline Suicides & 0.68 & 0.01 & $<0.001$ & 25 & 52 & 27 \\
\hline Drug overdoses & 0.74 & 0.01 & $<0.001$ & 7.7 & 8.2 & 8.4 \\
\hline Alcohol deaths & 0.46 & 0.01 & $<0.001$ & 36 & 88 & 35 \\
\hline Social capital ${ }^{\star}$ & 0.11 & 0.02 & $<0.001$ & 2.6 & 3.0 & 2.7 \\
\hline Foreign born & 0.34 & 0.02 & $<0.001$ & 13.7 & 31 & 12.7 \\
\hline White & 0.13 & 0.02 & $<0.001$ & 5.6 & 5.7 & 7.2 \\
\hline Population $^{+}$ & 0.40 & 0.02 & $<0.001$ & 6.5 & 7.6 & 6.4 \\
\hline Male unemployment & 0.30 & 0.02 & $<0.001$ & 2.4 & 2.6 & 2.4 \\
\hline Female unemployment & 0.14 & 0.02 & $<0.001$ & 3.0 & 3.5 & 3.8 \\
\hline Median household income & 0.23 & 0.02 & $<0.001$ & 3.8 & 4.2 & 4.4 \\
\hline Bachelors degree & 0.47 & 0.01 & $<0.001$ & 5.4 & 5.8 & 6.0 \\
\hline
\end{tabular}

Table S4: Weighted correlations between the fixed rates on all predictors used in the models in 2016 and the change in these rate between 2008 and 2016 using the 'wtd.cor' function in R 3.5.1. All changes (i.e. increases) were calculated as the difference between 2016 and 2008 except social capital which was calculated as the difference between 2014 and 2005^. The correlation between population in 2016 and the change in population from 2008 to 2016 was not weighted + . 
TRUMP VS CLINTON

SANDERS VS CLINTON

TRUMP VS KASICH

\begin{tabular}{|c|c|c|c|c|c|c|c|c|c|}
\hline \multirow[b]{2}{*}{ PREDICTOR } & \multirow{2}{*}{$\begin{array}{c}\text { COHEN'S d } \\
\text { X } \\
\text { SIGN(+/-) }\end{array}$} & \multicolumn{2}{|c|}{ HYPOTHESIS } & \multirow{2}{*}{$\begin{array}{c}\text { COHEN'S d } \\
\mathrm{X} \\
\text { SIGN(+/-) }\end{array}$} & \multicolumn{2}{|c|}{ HYPOTHESIS } & \multirow{2}{*}{$\begin{array}{c}\text { COHEN'S d } \\
\mathrm{X} \\
\text { SIGN(+/-) }\end{array}$} & \multicolumn{2}{|c|}{ HYPOTHESIS } \\
\hline & & $\begin{array}{c}\text { Pred } \\
+/-\end{array}$ & $\begin{array}{c}\text { Support } \\
\boldsymbol{V} / \boldsymbol{X}\end{array}$ & & $\begin{array}{c}\text { Pred } \\
+/-\end{array}$ & $\begin{array}{c}\text { Support } \\
\boldsymbol{V} / \boldsymbol{X}\end{array}$ & & $\begin{array}{c}\text { Pred } \\
+/-\end{array}$ & $\begin{array}{c}\text { Support } \\
\boldsymbol{V} / \boldsymbol{X}\end{array}$ \\
\hline \multicolumn{10}{|l|}{ Social change [2008-2016] } \\
\hline Increase in suicides & 0.19 & + & $\checkmark$ & 0.09 & + & $\checkmark$ & 0.04 & + & $\checkmark$ \\
\hline Increase in deaths dues to alcohol & 0.08 & + & $\boldsymbol{v}$ & 0.06 & + & $\checkmark$ & 0.03 & + & $\boldsymbol{v}$ \\
\hline Increase in drug overdoses & -0.07 & + & $x$ & -0.02 & + & $x$ & 0.03 & + & $\mathbf{x}$ \\
\hline Increase in social capital ${ }^{\star}$ & 0.14 & - & $\checkmark$ & 0.06 & - & $\checkmark$ & 0.05 & - & $\checkmark$ \\
\hline Mean Effect of Social factors & 0.09 & & $\checkmark$ & 0.05 & - & $\checkmark$ & 0.04 & & $\checkmark$ \\
\hline \multicolumn{10}{|l|}{ Demographic change [2008-2016] } \\
\hline Increase in percent foreign born & -0.03 & + & $x$ & -0.07 & + & $\boldsymbol{x}$ & -0.04 & + & $\boldsymbol{x}$ \\
\hline Increase in percent white & -0.42 & - & $\boldsymbol{x}$ & -0.11 & - & $\mathbf{x}$ & -0.18 & - & $\boldsymbol{x}$ \\
\hline Increase in population & 0.17 & - & $\checkmark$ & -0.07 & - & $\boldsymbol{x}$ & 0.25 & - & $\checkmark$ \\
\hline Mean Effect of Demographic factors & -0.09 & & $\boldsymbol{x}$ & -0.08 & & $\mathbf{x}$ & 0.01 & & $\boldsymbol{v}$ \\
\hline \multicolumn{10}{|l|}{ Economic change [2008-2016] } \\
\hline Increase in male unemployment & -0.11 & + & $\boldsymbol{x}$ & -0.04 & + & * & -0.05 & + & $\boldsymbol{x}$ \\
\hline Increase in female unemployment & 0.07 & + & $\boldsymbol{v}$ & 0.004 & + & $\checkmark$ & 0.03 & + & $\boldsymbol{v}$ \\
\hline Increase in median household income & -0.006 & - & $\boldsymbol{x}$ & -0.05 & - & $\boldsymbol{x}$ & 0.008 & - & $\checkmark$ \\
\hline Increase in percent with bachelors degree & 0.35 & - & $\checkmark$ & 0.05 & - & $\checkmark$ & 0.19 & + & $\checkmark$ \\
\hline Mean Effect of Economic factors & 0.08 & & $\checkmark$ & -0.01 & & $\checkmark$ & 0.04 & & $\checkmark$ \\
\hline
\end{tabular}

Table S5: Standardized effect sizes (Cohen's d)[16] and whether the parameter estimate supports the prediction for factors affecting the number of votes that Trump [1] received in comparison to Clinton [0] in 2016,that Sanders [1] received in comparison to Clinton [0] in the 2016 Democratic primary and that Trump [1] received in comparison to Kasich [0] in the 2016 Republican primary (left to right). Parameter estimate means and $97.5 \%$ credibility intervals are show in Supplementary materials: Tables S1-S3. All changes (i.e. increases) were calculated as the difference between 2016 and 2008 except social capital which was calculated as the difference between 2014 and 2005`. Suicides, drug overdoses and deaths due to alcohol are entered as rates per 100,000 individuals and were obtained from the Center for Disease control. Social capital is centered at zero and a one point difference in either direction represents one standard deviation. Population and median household income were both logged. Percent with a bachelors degree, percent foreign born, household income, unemployment rates, percent white and population are based on estimates from the Census Bureau American Community Surveys (ACS) from 2008 and 2016. 
A

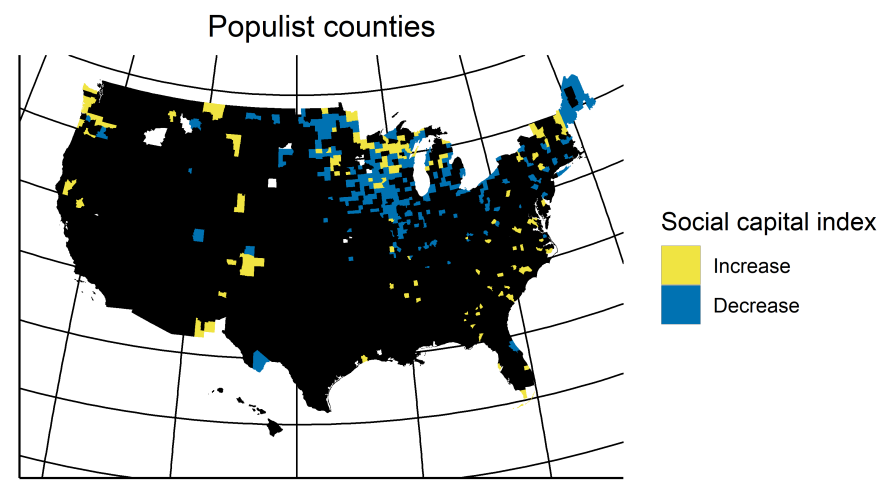

B

Traditional counties

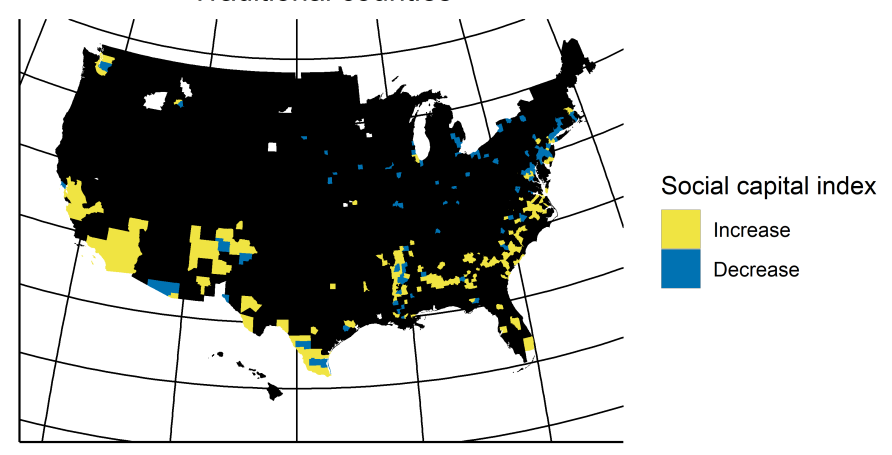

Figure S1: Populist (top panel) and traditional (bottom panel) counties in which overall social capital has increased (yellow) and decreased (blue) between 2005 and 2014. Counties were categorized as 'populist' if they voted for Trump in the 2016 general election while also voting for Obama against McCain in the 2008 presidential election and if they voted for Sanders in the 2016 DNC primary. Non-populist in top panel and non-traditional counties in bottom panel are colored black. The social capital index decreased more in 'populist' counties than in 'traditional' counties P4 (see Materials and Methods: Categorizing counties as 'populist' (mean decrease of -0.22, S.E. +/- 0.04 vs. a mean increase of 0.14, S.E. +/- 0.01 (see Figure 1A).For interactive version with all counties and data for all variables used in the models click Fig S1 


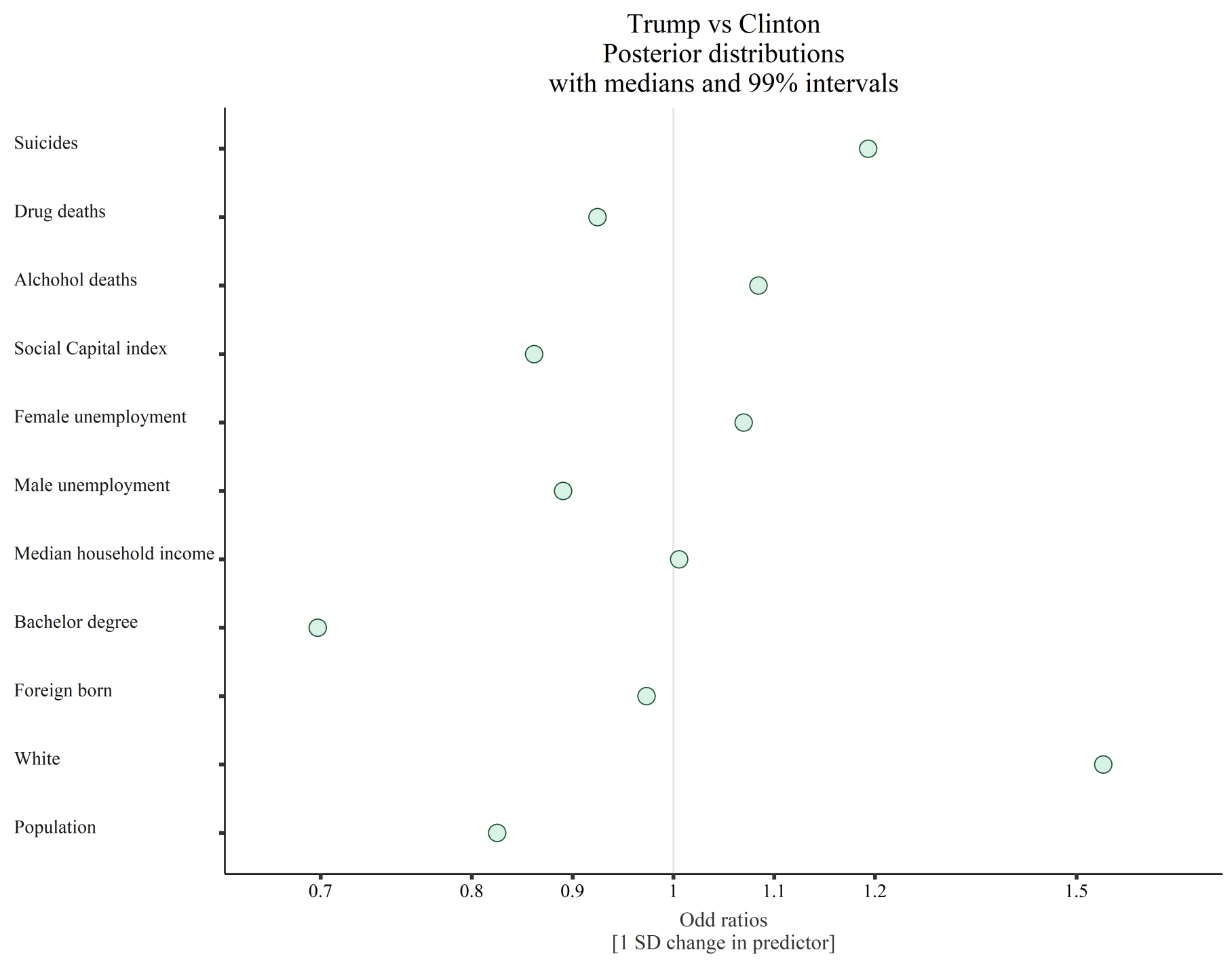

Figure S2a: Posterior distributions medians and 99\% credibility intervals for number of votes for Trump vs. Clinton in the 2016 General election. The predictors are on different scales and have therefore been standardized across their range (e.g. multiplied by their observed range) to compare their relative effects on the likelihood of voting for Trump[17]. All fixed effects entered into the model (states were entered as a random effect) are shown and display the entire distribution of 6000 sample draws from the posterior distribution. Parameter estimates have been converted to odds ratios (X-axis) (i.e. the proportional change in the outcome induced by each predictor). See Supplementary materials: Table S1 for parameter estimates, $97.5 \%$ Highest Density Intervals and Odds ratios for these predictors. 


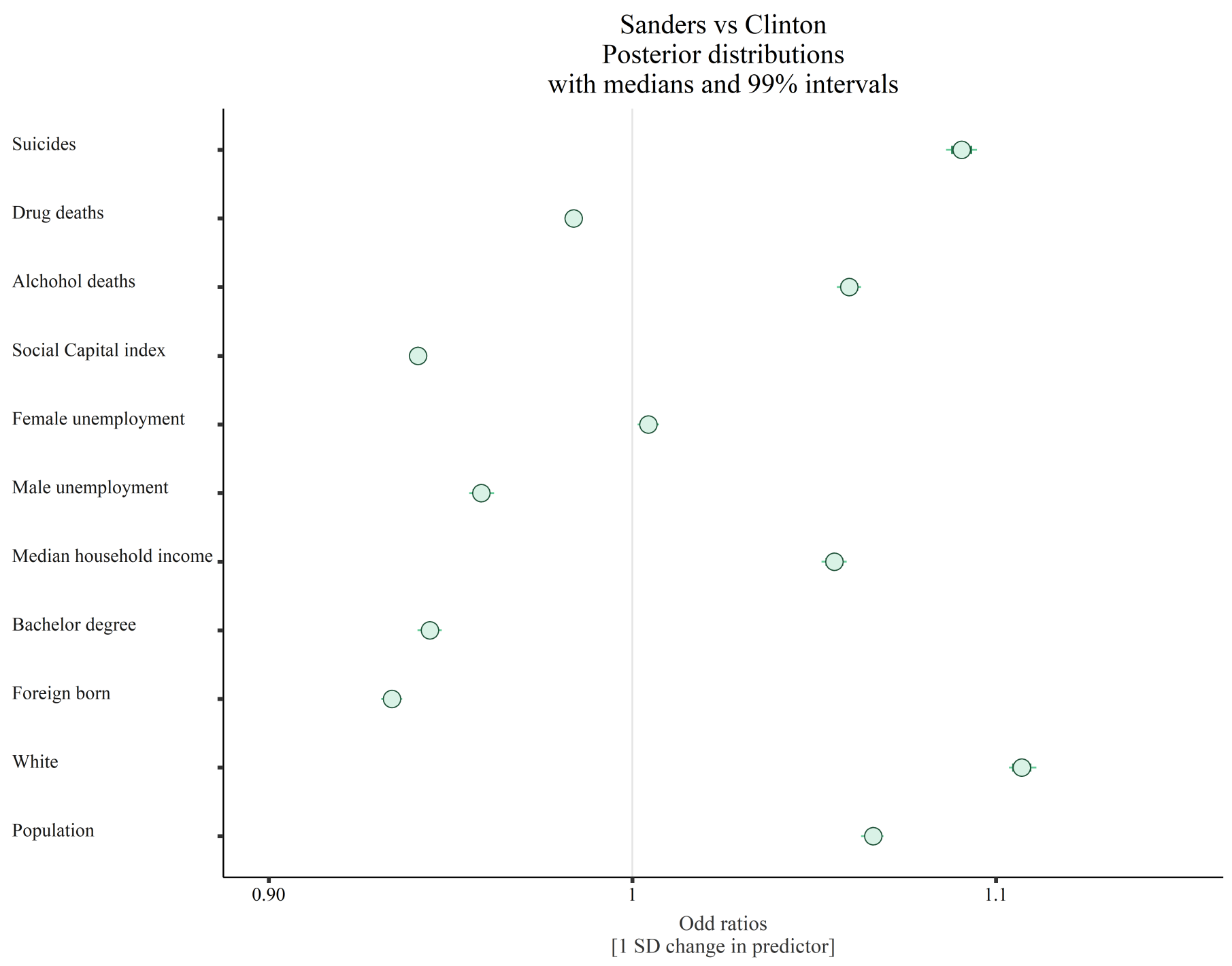

Figure S2b: Posterior distributions medians and 99\% credibility intervals for number of votes for Sanders vs. Clinton in the 2016 Democratic primary. The predictors are on different scales and have therefore been standardized across their range (e.g. multiplied by their observed range) to compare their relative effects on the likelihood of voting for Sanders[17]. All fixed effects entered into the model (states were entered as a random effect) are shown and display the entire distribution of 6000 sample draws from the posterior distribution. Parameter estimates have been converted to odds ratios (X-axis) (i.e. the proportional change in the outcome induced by each predictor). See Supplementary materials: Table S2 for parameter estimates, 97.5\% Highest Density Intervals and Odds ratios for these predictors. 


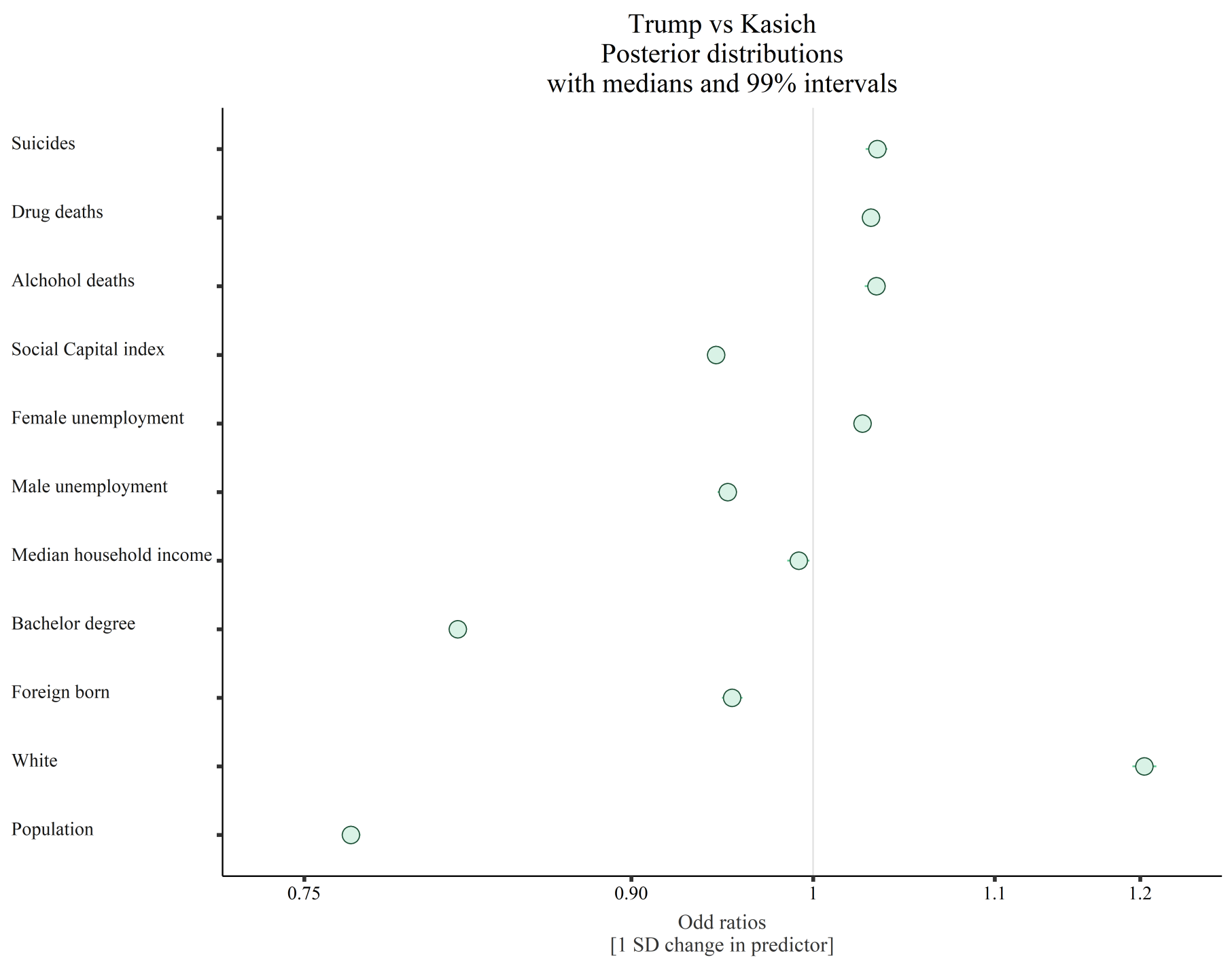

Figure S2c: Posterior distributions medians and 99\% credibility intervals for number of votes for Trump vs. Kasich in the 2016 Republican primary. The predictors are on different scales and have therefore been standardized across their range (e.g. multiplied by their observed range) to compare their relative effects on the likelihood of voting for Trump[17]. All fixed effects entered into the model (states were entered as a random effect) are shown and display the entire distribution of 6000 sample draws from the posterior distribution. Parameter estimates have been converted to odds ratios (X-axis) (i.e. the proportional change in the outcome induced by each predictor). See Supplementary materials: Table S3 for parameter estimates, 97.5\% Highest Density Intervals and Odds ratios for these predictors. 


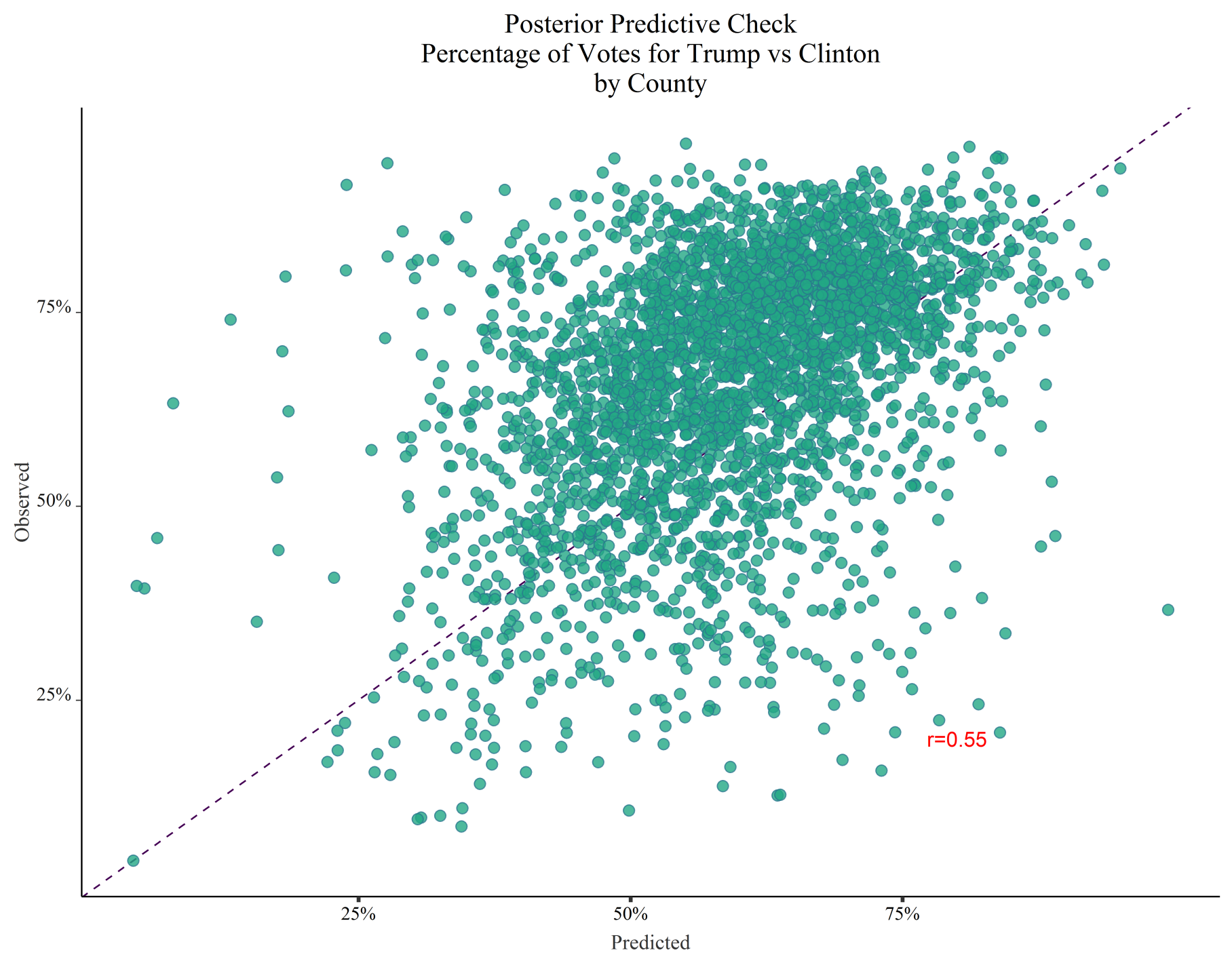

Figure S3a: Posterior predictive check for model Trump vs Clinton in the 2016 general election (Table S1). The scatter are how counties actually voted (Y-axis: Observed) vs how the model predicts these counties will vote (X-axis: Predicted). The correlation between the observed data and the model predictions $(\mathrm{r}=0.55)$ suggests that the model does a reasonably good job of reverse engineering the data which indicates that the model is specified correctly. 


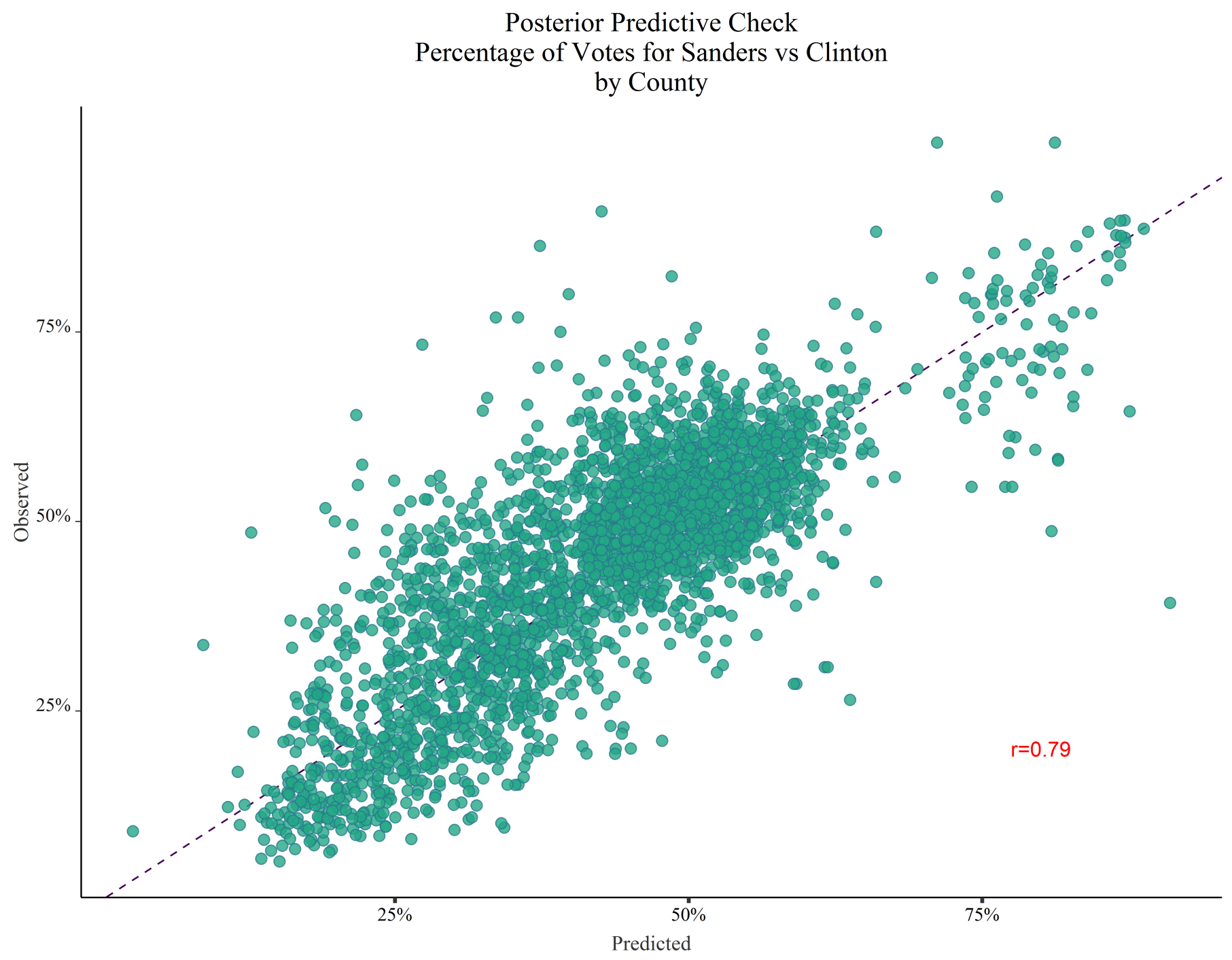

Figure S3b: Posterior predictive check for model Sanders vs Clinton in the 2016 Democratic primary (see Table S2). The scatter are how counties actually voted (Y- axis: Observed) vs how the model predicts these counties will vote (X-axis: Predicted). The correlation between the observed data and the model predictions $(\mathrm{r}=0.79)$ suggests that the model does a reasonably good job of reverse engineering the data which indicates that the model is specified correctly. 


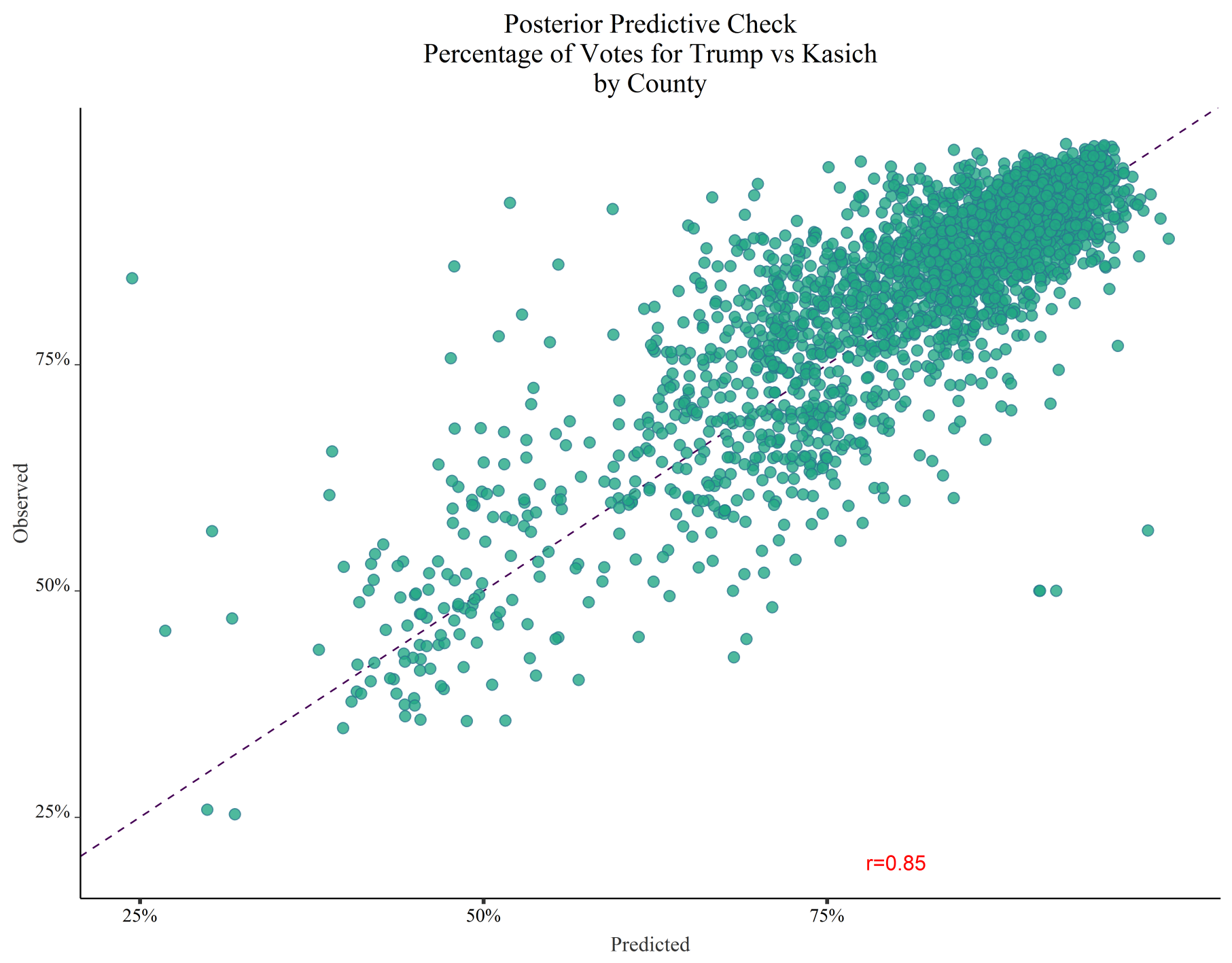

Figure S3c: Posterior predictive check for model Trump vs Kasich in the 2016 Republican primary (see Table S4). The scatter are how counties actually voted (Y- axis: Observed) vs how the model predicts these counties will vote (X-axis: Predicted). The correlation between the observed data and the model predictions $(r=0.85)$ suggests that the model does a reasonably good job of reverse engineering the data which indicates that the model is specified correctly. 
Trace plots for Trump Clinton

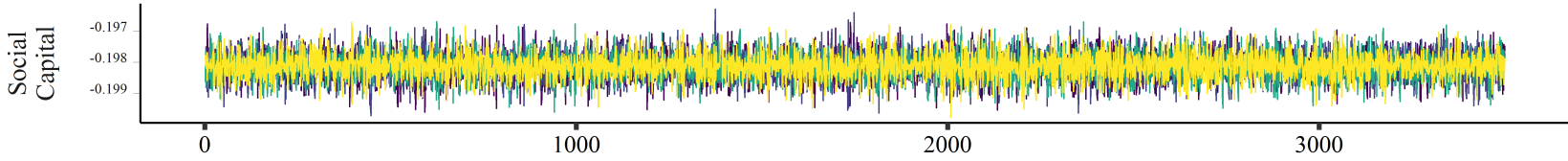

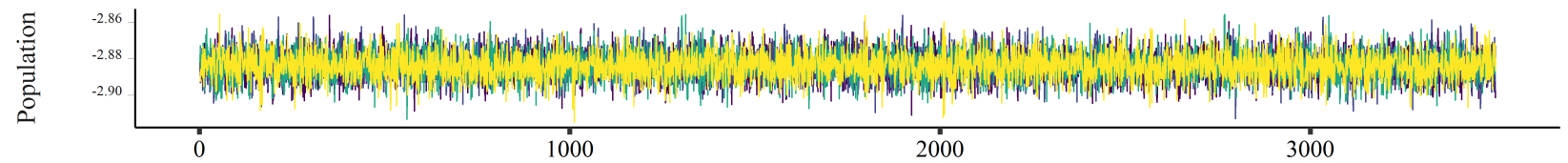

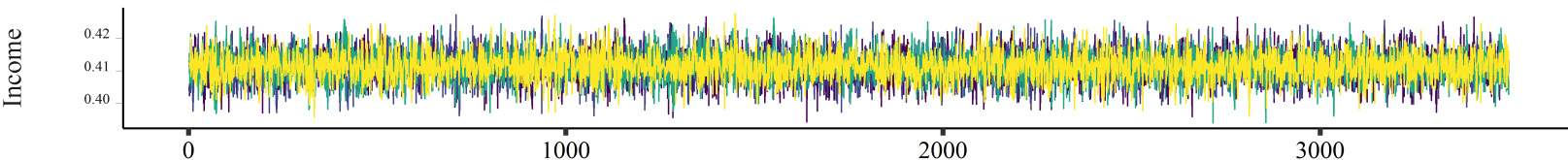

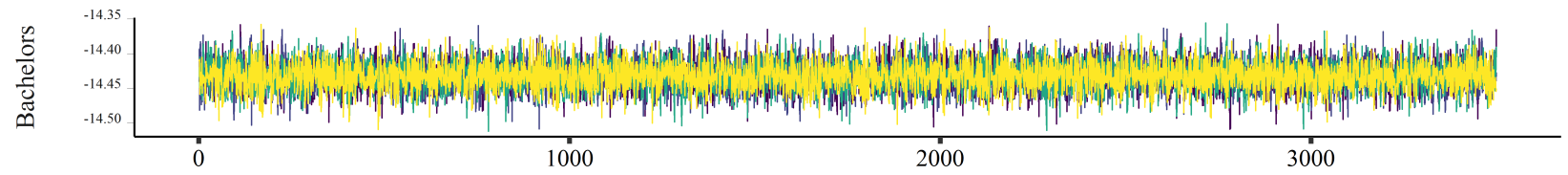

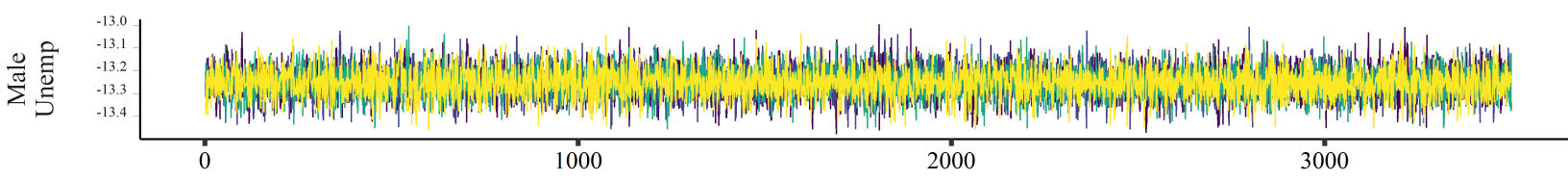
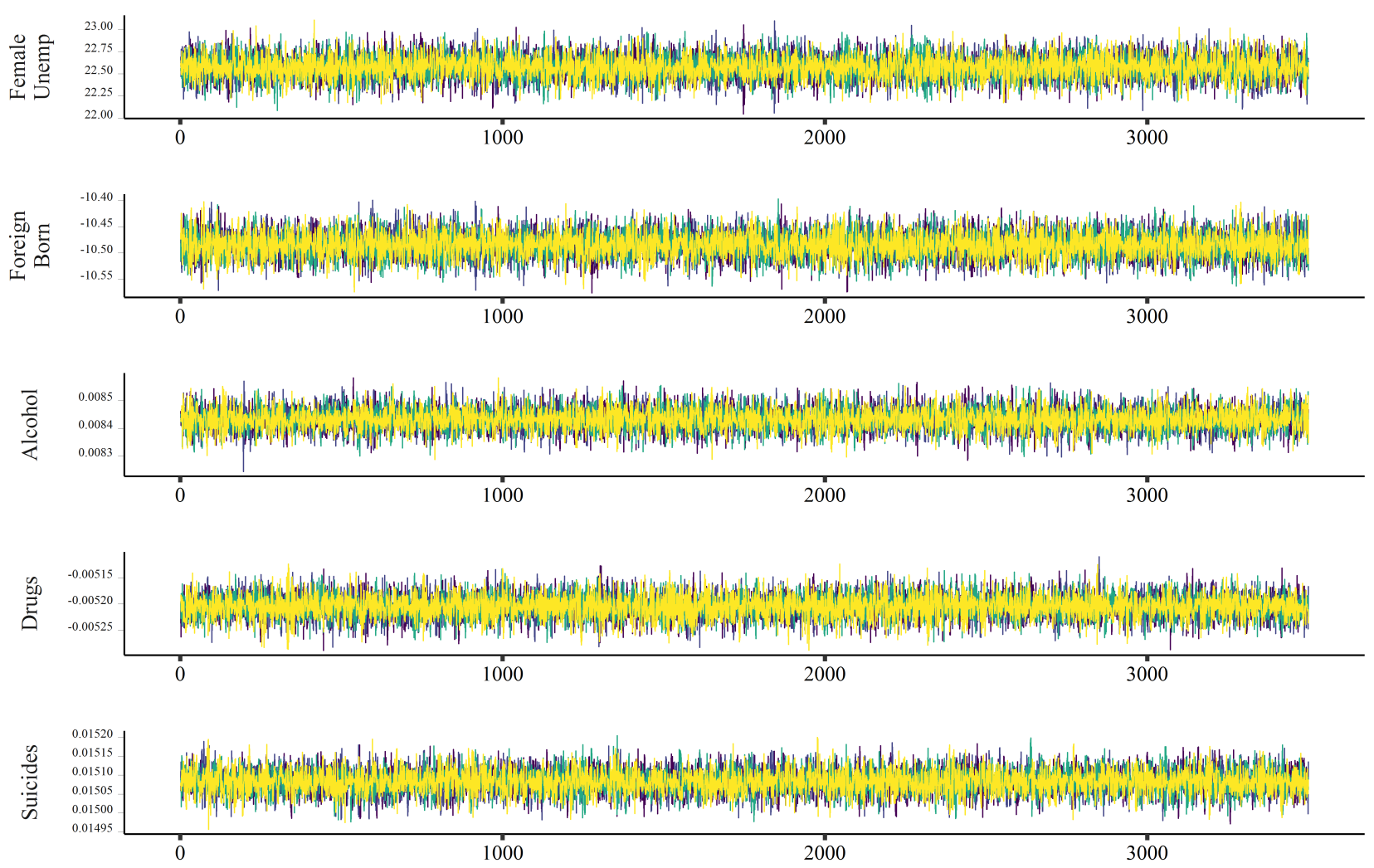

Figure S4a: Trace plots showing convergence of Markov chains for all fixed effects entered into the model predicting number of votes for Trump vs Clinton in the general election. 
Trace plots for sanders Clinton
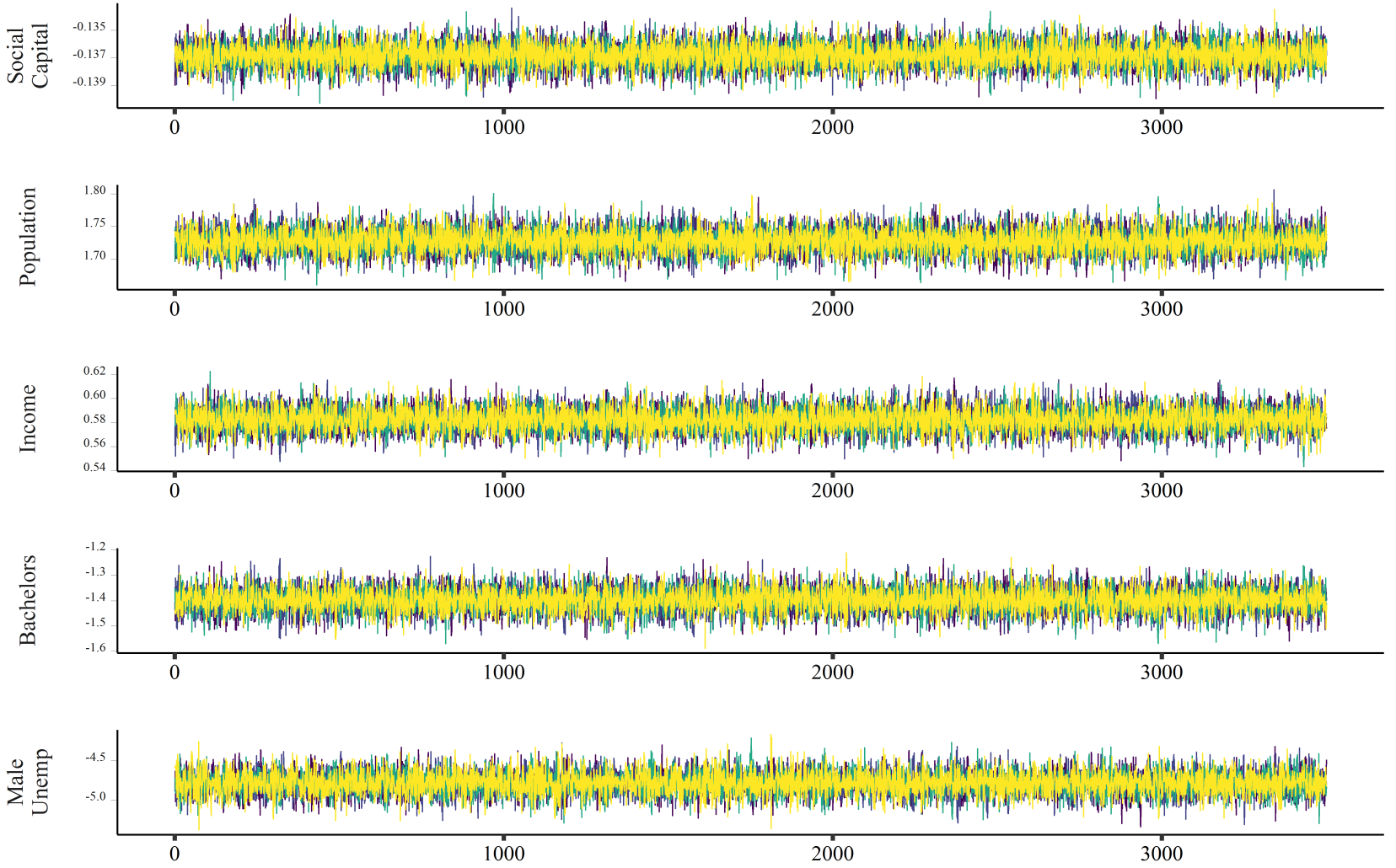

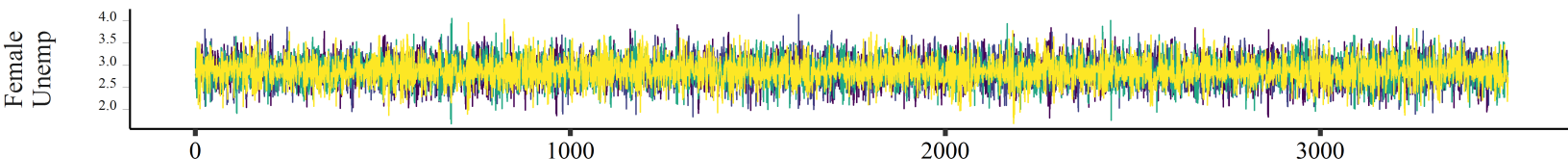

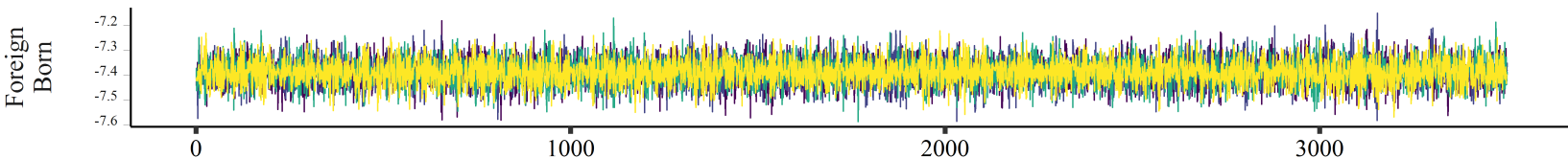
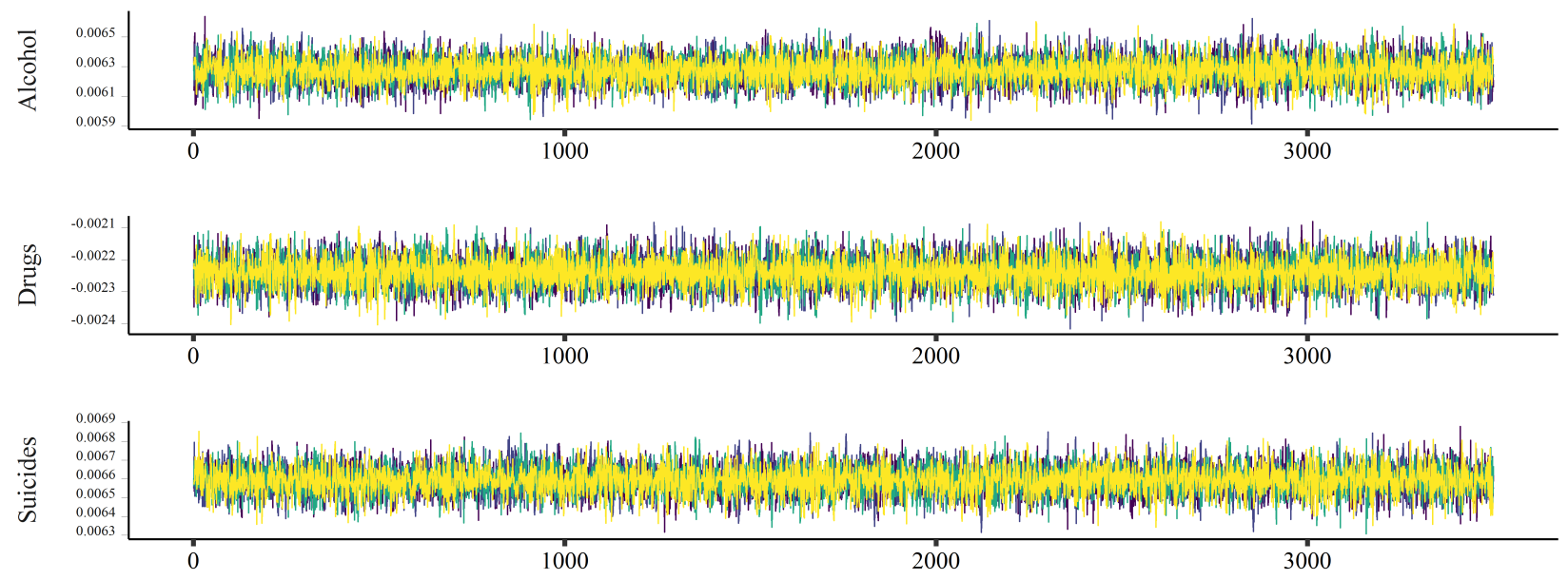

Figure S4b: Trace plots showing convergence of Markov chains for all fixed effects entered into the model predicting number of votes for Sanders vs Clinton in the Democratic primary. 
Trace plots for Trump Kasich
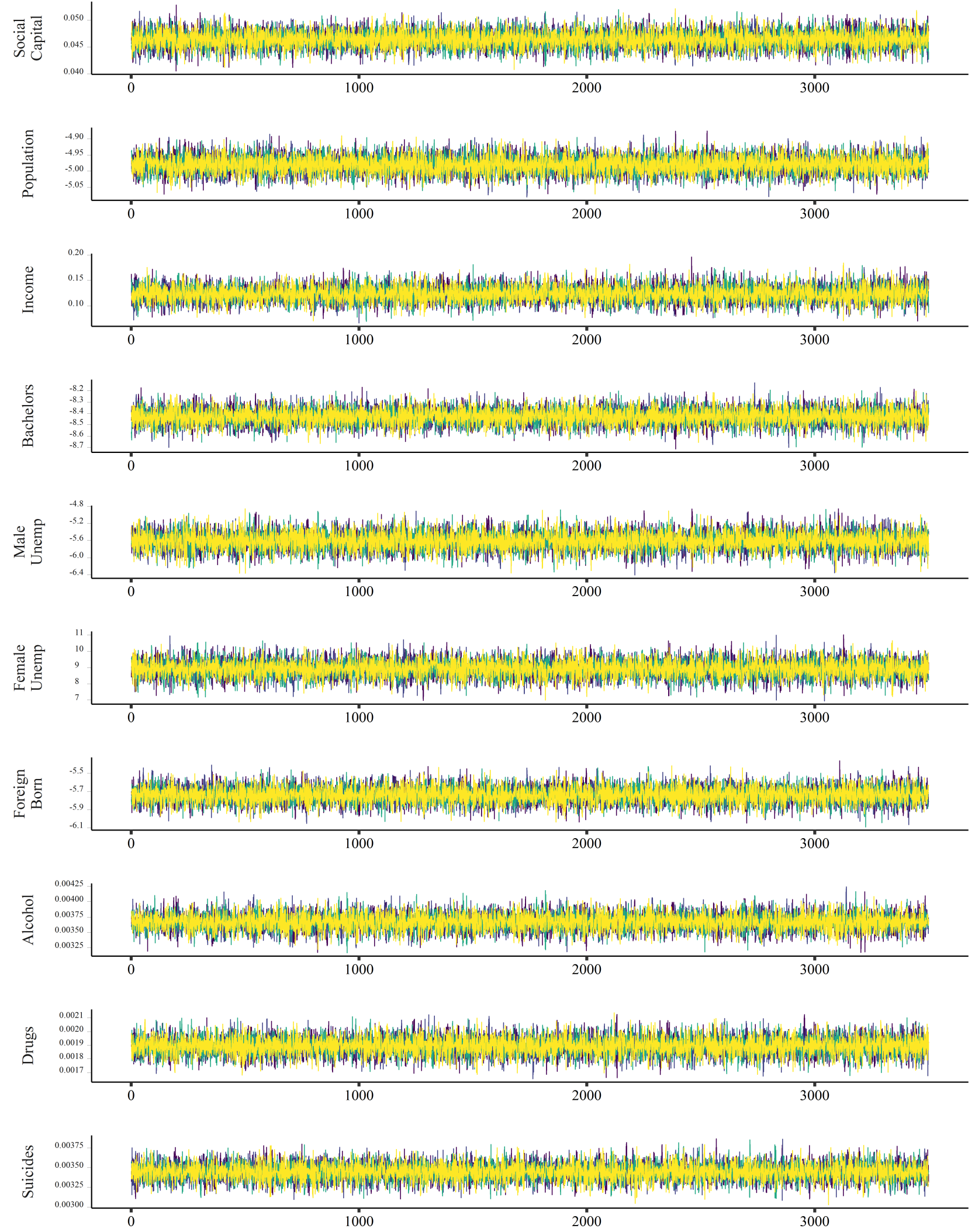

Figure S4c: Trace plots showing convergence of Markov chains for all fixed effects entered into the model predicting number of votes for Trump vs Kasich in the Republican primary. 